MARIA LUIZA NOGUEIRA DIAS GENTA

\title{
Farmacocinética e captação tecidual do paclitaxel associado à nanoemulsão (LDE) em pacientes com neoplasias malignas do trato genital feminino
}

Dissertação apresentada à Faculdade de Medicina da Universidade de São Paulo para obtenção do título de Mestre em Ciências

Área de concentração: Obstetrícia e Ginecologia Orientador: Prof. Dr. Jesus Paula Carvalho

São Paulo

2006 


\section{FICHA CATALOGRÁFICA}

Preparada pela Biblioteca da

Faculdade de Medicina da Universidade de São Paulo

Creprodução autorizada pelo autor

Genta, Maria Luiza Nogueira Dias

Farmacocinética e captação tecidual do paclitaxel associado à nanoemulsão (LDE) em pacientes com neoplasias malignas do trato genital feminino / Maria Luiza Nogueira Dias Genta. -- São Paulo, 2006.

Dissertação(mestrado)--Faculdade de Medicina da Universidade de São Paulo. Departamento de Obstetrícia e Ginecologia.

Área de concentração: Obstetrícia e Ginecologia.

Orientador: Jesus Paula Carvalho.

Descritores: 1.PACLITAXEL 2.EMULSÕES 3.LIPOPROTEÍNAS LDL 4.QUIMIOTERAPIA 5.SISTEMAS DE LIBERAÇÃO DE MEDICAMENTOS 6.NEOPLASIAS DO COLO UTERINO 7.NEOPLASIAS DO ENDOMÉTRIO 8.NEOPLASIAS OVARIANAS

USP/FM/SBD-089/06 
A Pedro, Felipe e Luiza. 


\section{AgRADECIMENTO ESPECIAL}

Ao Prof. Dr. Raul Cavalcante Maranhão, digníssimo Professor Titular da Faculdade de Ciências Farmacêuticas da Universidade de São Paulo, pela oportunidade de participar de sua linha de pesquisa e pelas orientações dadas na elaboração deste trabalho. 


\section{AgRAdecimentos}

Ao Prof. Dr. Jesus Paula Carvalho, digníssimo Professor Livre-Docente de Ginecologia do Departamento de Ginecologia e Obstetrícia da Faculdade de Medicina da Universidade de São Paulo, pelo incentivo constante e compreensão.

Ao Prof. Dr. Edmund Chada Baracat, digníssimo Professor Titular de Ginecologia do Departamento de Ginecologia e Obstetrícia da Faculdade de Medicina da Universidade de São Paulo pelas valiosas observações feitas na fase final desta dissertação.

À Prof ${ }^{a}$. Dra. Ângela Maggio da Fonseca, pelo incentivo incansável à pesquisa científica.

Ao Prof. Dr. Maurício Simões Abrão e Prof. Dr. Paulo Levy Schivartche, pelas valiosas observações feitas na fase de Qualificação desta pesquisa.

À Dra. Débora Garcia Rodrigues pela valiosa orientação na condução laboratorial desta pesquisa, pelos muitos momentos compartilhados e pela generosa amizade.

Aos funcionários do Laboratório de Lípides do Instituto do Coração (Incor) do Hospital das Clínicas da Universidade de São Paulo pelo amigável contato e prestimosa cooperação. 
À secretária da Pós-Graduação, Srta. Cláudia Aparecida Vieira, pela dedicação e atenção constantes, e por sempre auxiliar com a burocracia acadêmica.

Aos colegas do Setor de Oncologia Ginecológica da Clínica Ginecológica do Hospital das Clínicas da Faculdade de Medicina da Universidade de São Paulo (HCFMUSP), pelo constante apoio e pela prestativa colaboração.

Aos meus queridos pais, Mario e Maria Aparecida, pela dedicação, amor e incentivo ao longo de minha vida.

À minha irmã Maria Carolina e minha avó Santa, pela presença constante nos momentos de ajuda familiar.

Aos meus sogros, Edison e Marly, pelo amor e dedicação ao Felipe, proporcionando preciosos períodos de estudo.

Ao meu querido marido, companheiro e amigo, por todos os momentos compartilhados durante esta pesquisa.

Aos meus filhos, Felipe, pela paciência de dividir a mãe com suas atividades acadêmicas; e Luiza, presente em toda a fase final deste estudo.

Às pacientes, sem as quais esta pesquisa não teria se concretizada. 
"Aceita as surpresas

que transformam teus planos,

derrubam teus sonhos,

dão rumo totalmente diverso

ao teu dia e, quem sabe,

à tua vida."

D. Hélder Câmara 
Esta dissertação está de acordo com:

Referências: adaptado de International Committee of Medical Journals Editors (Vancouver)

Universidade de São Paulo. Faculdade de Medicina. Serviço de Biblioteca e Documentação. Guia de apresentação de dissertações, teses e monografias. Elaborado por Anneliese Carneiro da Cunha, Maria Julia de A. L. Freddi, Maria F. Crestana, Marinalva de Souza Aragão, Suely Campos Cardoso, Valéria Vilhena. São Paulo: Serviço de Biblioteca e Documentação; 2005.

Abreviaturas dos títulos dos periódicos de acordo com List of Journals Indexed in Index Medicus. 


\section{SUMÁRIO}

1 INTRODUÇÃO

1.1 Quimioterapia e neoplasia do trato genital feminino ................. 1

1.1.1 Câncer como problema de saúde pública ........................ 1

1.1.2 Câncer do colo uterino ................................................. 1

1.1.3 Câncer de ovário ........................................................... 3

1.1.4 Câncer de endométrio ..................................................... 5

1.1.5 Novas perspectivas de tratamento quimioterápico .......... 7

1.2 LDL e Câncer ..................................................................... 8

1.2.1 Lipoproteína ............................................................... 8

1.2.2 Lipoproteína de baixa densidade .................................... 8

1.2.3 Lipoproteína e câncer ................................................... 10

1.2.4 LDL como agente direcionador de fármaco .................... 13

1.2.5 Nanoemulsão lipídica artificial (LDE) .............................. 13

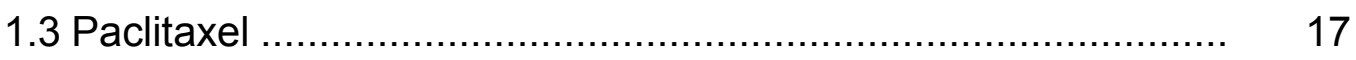

1.3.1 Histórico do Fármaco ................................................... 17

1.3.2 Novas formulações e síntese de pró-fármacos ............... 20

2 OBJETIVOS ............................................................................. 24

3 MÉTODOS …........................................................................ 25

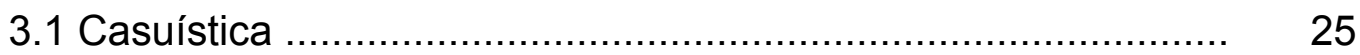

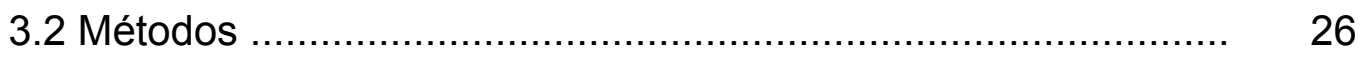

3.2.1 Preparo da emulsão LDE-paclitaxel e apresentação comercial do paclitaxel

3.2.1.1 Preparação da nanoemulsão LDE marcada com $\left[{ }^{14} \mathrm{C}\right]$-oleato de colesterol

3.2.1.2 Síntese do $\left[{ }^{3} \mathrm{H}\right]$-oleato de paclitaxel

28

3.2.1.3 Incorporação de $\left[{ }^{3} \mathrm{H}\right]$-oleato de paclitaxel na LDE $\quad 29$

3.2.1.4 Preparação da apresentação comercial do paclitaxel

3.2.2 Determinação da cinética plasmática da associação $\left[{ }^{14} \mathrm{C}\right]-\mathrm{LDE}-\left[{ }^{3} \mathrm{H}\right]$-oleato de paclitaxel

3.2.3 Determinação da cinética plasmática do fármaco $\left[{ }^{3} \mathrm{H}\right]-$ paclitaxel 
3.2.4 Procedimento cirúrgico e obtenção dos fragmentos

3.2.5 Extração de lípides - captação tecidual de $\left[{ }^{14} C\right]-L D E$ $\left[{ }^{3} \mathrm{H}\right]$-oleato de paclitaxel

3.2.6 Determinações bioquímicas séricas ………………....... 34

3.3 Análise estatística ........................................................ 36

4 RESULTADOS ….................................................................... 37

4.1 Cinética dos componentes marcados radiaotivamente: $\left[{ }^{14} \mathrm{C}\right]-$ LDE, $\left[{ }^{3} \mathrm{H}\right]$-oleato de paclitaxel e apresentação comercial $\left[{ }^{3} \mathrm{H}\right]$ - paclitaxel

4.2 Parâmetros farmacocinéticos do oleato de paclitaxel e paclitaxel comercial

4.3 Extração de lípides - captação tecidual de $\left[{ }^{14} \mathrm{C}\right]-\mathrm{LDE} \times\left[{ }^{3} \mathrm{H}\right]-$ oleato de paclitaxel

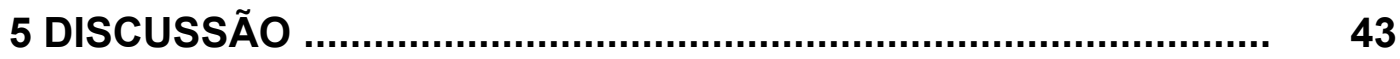

6 CONCLUSÕES ……............................................................. 49

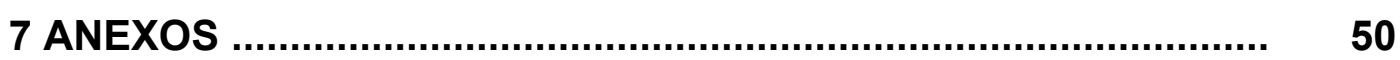

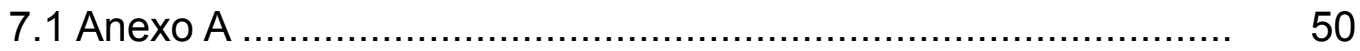

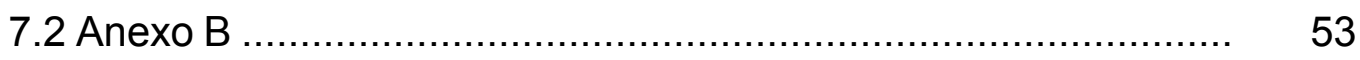

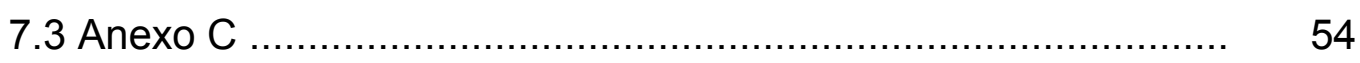

8 REFERÊNCIAS …................................................................. 62 
Genta, MLND. Farmacocinética e captação tecidual do paclitaxel associado à nanoemulsão (LDE) em pacientes com neoplasias malignas do trato genital feminino [tese]. São Paulo: Faculdade de Medicina, Universidade de São Paulo; 2006. 78 p.

O paclitaxel é utilizado amplamente no carcinoma de ovário, nos casos refratários de carcinoma de endométrio e quimioterapia exclusiva para carcinoma avançado de colo uterino. A toxicidade deste fármaco é fator limitante para seu emprego em alguns casos. A associação de paclitaxel a uma nanoemulsião rica em colesterol, denominada LDE, mostrou menor toxicidade e aumento da atividade antitumoral do fármaco quando testado em modelo murino de melanoma B16. No presente estudo, investigou-se os parâmetros farmacocinéticos do oleato de LDE-paclitaxel e a habilidade da LDE de concentrar a droga no tumor em oito pacientes com neoplasia do trato genital femino. Determinou-se as curvas da taxa de remoção fracionária (FCR) e os parâmetros farmacocinéticos: tempo de meia-vida $\left(T_{1 / 2}\right)$, "clearance" plasmático (Cl), área sob a curva (AUC) e volume de distribuição $\left(V_{s s}\right)$. Os fragmentos de tecidos tumorais e normais correspondentes obtidos durante cirurgia também foram analisados quanto à captação radioativa do LDE, paclitaxel e a sua associação. A taxa de FCR do LDE e da associação LDE-paclitaxel eram similares $\left(0,092\right.$ e $0,069 \mathrm{~h}^{-1}$, respectivamente, $\mathrm{n}=5$ e $\mathrm{p}=$ $0,390)$. A FCR do oleate de paclitaxel associado à LDE era menor do que aquele do paclitaxel comercial $\left(0,231 \mathrm{~h}^{-1}, \mathrm{p}=0,028\right)$. $O \mathrm{~T}_{1 / 2}$ e a AUC do LDEpaclitaxel eram maiores do que as do paclitaxel comercial $\left(T_{1 / 2}=14,51 \mathrm{e}\right.$ $6,62 \mathrm{~h}$ e $A U C=2,49$ e 1,26 $\mathrm{ng} / \mathrm{h} / \mathrm{L}$, respectivamente $\mathrm{p}=0,009, \mathrm{p}=0,004)$. A quantidade de LDE-paclitaxel e de LDE no tumor foi, respectivamente, 3,6 e 3,5 vezes maior do que nos tecidos normais correspondentes. A associação à LDE parece ser estratégia interessante para usar o paclitaxel no tratamento dos tumores ginecológicos.

Palavras chaves: Paclitaxel, Nanoemulsão, Lipoproteína de baixa densidade (LDL), Drogas alvo, Quimioterapia, Neoplasia maligna do trato genital feminino 
Genta MLND. Pharmacokinetics and tumor uptake of a derivatized form of paclitaxel associated to a cholesterol-rich nanoemulsion (LDE) in patients with gynecologic cancers [tese]. São Paulo: "Faculdade de Medicina, Universidade de São Paulo"; 2006. 78 p.

A cholesterol-rich nanoemulsion termed LDE concentrates in cancer tissues after injection into the bloodstream. The association of a derivatized paclitaxel to LDE showed lower toxicity and increased antitumoral activity as tested in a B16 melanoma murine model. Here, the pharmacokinetics of LDE-paclitaxel oleate and the ability of LDE to concentrate the drug in the tumor were investigated in eight patients with gynecologic cancers. Blood samples were collected over $24 \mathrm{~h}$ to determine the plasma decay curves. Fractional clearance rate (FCR) and pharmacokinetic parameters were calculated by compartmental analysis. Also, specimens of tumors and the corresponding normal tissues were excised during the surgery for radioactivity measurement. The LDE and paclitaxel oleate FCR were similar (0.092 \pm 0.039 and $0.069 \pm 0.027 \mathrm{~h}^{-1}$, respectively, $\left.\mathrm{n}=5, p=0.390\right)$. FCR of paclitaxel oleate associated to LDE was smaller than that of commercial paclitaxel $\left(0.231 \pm 0.128 \mathrm{~h}^{-1}, p=0.028\right)$. Paclitaxel oleate $\mathrm{T}_{1 / 2}$ and AUC were greater than those of commercial paclitaxel $\left(T_{1 / 2}=14.51 \pm 3.23\right.$ and $6.62 \pm$ $2.05 \mathrm{~h}$ and $\mathrm{AUC}=2.49 \pm 0.35$ and $1.26 \pm 0.40 \mathrm{ng} / \mathrm{h} / \mathrm{L}$, respectively $p=0.009$, $p=0.004$ ). The amount of paclitaxel and LDE radioactive labels in the tumor was 3.5 and 3,6 times greater than in the normal tissues. Paclitaxel oleate associated to LDE is stable in the bloodstream and has greater plasma halflife and AUC than those for commercial paclitaxel. LDE concentrates 3.5 more paclitaxel in malignant tissues than in the normal tissues. Therefore, association to LDE is an interesting strategy for using paclitaxel to treat gynecologic cancers.

Key Words: Paclitaxel, Emulsions, Low-density lipoprotein (LDL) receptors, Drug targeting, Chemotherapy, Gynecologic cancer. 


\section{INTRODUÇÃO}

\subsection{QUIMIOTERAPIA E NEOPLASIA DO TRATO GENITAL FEMININO}

\subsubsection{CÂNCER COMO PROBLEMA DE SAÚDE PÚBLICA}

Parkin $^{1}$ et al. (2001) observaram que, no ano de 2000, o número de casos novos de câncer no mundo era superior a 10 milhões. Dentre estes, $53 \%$ ocorreram nos países em desenvolvimento.

Os tumores de pulmão (902.000 casos novos) e de próstata (543.000) foram os mais freqüentes no sexo masculino, enquanto no feminino observou-se as maiores ocorrências nos tumores de mama (1.000.000 de casos novos) e trato genital feminino: colo do útero (471.000), ovário (192.000) e endométrio (189.000).

No Brasil, segundo dados do Instituto Nacional do Câncer (INCA), ocorreram 467.440 casos novos de câncer em 2005. Os tipos mais incidentes, à exceção de pele não melanoma, são os de próstata e pulmão no sexo masculino e, mama e colo do útero, no feminino, acompanhando a mesma magnitude observada no mundo (INCA $\left.{ }^{2}, 2005\right)$.

\subsubsection{CÂNCER DO COLO DO ÚTERO}

O número de casos novos de câncer de colo do útero ocorridos no Brasil em 2005 foi de 20.690, com risco estimado de 22 casos a cada 
100.000 mulheres. Baseado no informe epidemiológico do INCA ${ }^{2}$ (2005) sem considerar os tumores de pele não melanoma, o câncer de colo do útero é o mais incidente na região Norte $(23 / 100.000)$ e, o segundo, nas regiões Sul (31/100.000), Centro-Oeste (23/100.000), Sudeste (22/100.000) e Nordeste $(18 / 100.000)$

A incidência do câncer de colo uterino torna-se importante na faixa etária de 20 a 29 anos, aumentando rapidamente até atingir seu pico entre 45 e 49 anos. Quase $80 \%$ dos casos novos ocorrem em países em desenvolvimento onde, em algumas regiões, é o mais comum entre as mulheres (Parkin ${ }^{1}$ et al., 2001; INCA ${ }^{2}$, 2005).

A mortalidade por essa afecção é substancialmente menor do que a sua incidência. Em países desenvolvidos, a sobrevida média estimada em cinco anos varia de 59 a 69\%. Nos países em desenvolvimento, os casos são encontrados em estádios relativamente avançados e, conseqüentemente, a sobrevida média é menor, cerca de $49 \%$ após cinco anos.

A redução da mortalidade e a incidência por câncer de colo de útero é possível por meio do exame citológico cervicovaginal pela técnica de Papanicolaou periódico e detecção precoce das lesões precursoras com alto potencial de malignidade ou carcinoma "in situ", mediante programas estruturados de rastreamento.

O inquérito domiciliar, conduzido pelo INCA, mostrou que para as 16 localidades analisadas, a cobertura estimada do exame Papanicolaou variou entre $74 \%$ e $93 \%$. Entretanto, o percentual de realização deste exame pelo 
SUS oscilou de $33 \%$ a $64 \%$ do total. Este achado, em parte explica 0 diagnóstico tardio e a manutenção das taxas de mortalidade, bem como as altas taxas de incidência observadas no Brasil (INCA $\left.{ }^{3}, 2003\right)$.

Diante de tal panorama, a terapêutica do carcinoma de colo uterino em estádios mais avançados ainda é muito comum e está baseada na radioterapia e quimioterapia de forma isolada ou em associação $\left(\mathrm{NCl}^{4}, 1999\right)$.

Recentemente, Buda ${ }^{5}$ et al. (2005) propuseram nova combinação de quimioterápicos para o tratamento neoadjuvante de pacientes com estádios entre IIB e IIIB (Federação Internacional de Ginecologia e Obstetrícia FIGO). O paclitaxel foi associado à cisplatina e à ifosfamida e comparado com o esquema tradicional: cisplatina e ifosfamida. O esquema de três fármacos apresentou taxa de resposta patológica ótima em $43 \%$ versus $23 \%$ encontrados no tratamento com dois fármacos. Tais dados indicam que o uso do paclitaxel constitui nova opção no tratamento do carcinoma de colo uterino.

\subsubsection{CÂNCER DE OVÁRIO}

O câncer de ovário é a neoplasia ginecológica menos diagnosticada nos estádios iniciais: cerca de $3 / 4$ dos tumores malignos de ovário apresentam-se em estágio avançado no momento do diagnóstico. Segundo Parkin ${ }^{1}$ et al. (2001) é o câncer ginecológico de maior letalidade, sendo responsável pela morte de 114.000 mulheres no ano de 2000 . 
É a sexta neoplasia maligna mais freqüente e a quarta causa de morte por câncer em mulheres nos Estados Unidos; em 2004 eram esperados 25580 novos casos, com 16090 óbitos (Jemal ${ }^{6}$ et al., 2004).

Os dados de prevalência acumulada ao longo da vida, desde o nascimento até 85 anos de idade, mostram que a probabilidade de ocorrência do câncer de ovário é de 1,5\% (Whittemore $\left.{ }^{7}, 1994\right)$ e a sobrevida global de apenas 30 a $40 \%$ em cinco anos.

Isto ocorre em parte porque a maioria das pacientes tem a doença diagnosticada em estádios avançados, situação em que as opções de tratamento são restritas à cirurgia citorredutora e à quimioterapia baseada nos derivados da platina. Estas modalidades terapêuticas são apenas parcialmente efetivas e, conseqüentemente, a maioria das pacientes apresentará recorrência e óbito por causa da doença (Jemal ${ }^{6}$ et al., 2004).

Os fatores de prognóstico, em geral, refletem a extensão da doença (estádio), a biologia intrínseca do tumor (tipo e grau histológico) e a capacidade da paciente tolerar o tratamento. Assim como estes fatores, outros ainda podem ter impacto na sobrevida, como o tipo de tratamento recebido (citorredução ótima, quimioterapia adequada) e o efeito da terapêutica sobre o tumor (exemplo: resposta completa) ou sobre a paciente (exemplo: mielossupressão), conforme dados descritos por Agarwal e Kaye ${ }^{8}$, em 2005.

Entre os fatores prognósticos, o estadiamento da FIGO é considerado o mais importante. A sobrevida em cinco anos é de $95 \%$ para os casos de tumor localizado no ovário, $72 \%$ para os com implantação regional e $31 \%$ 
para aqueles com tumor disseminado. No entanto, no momento do diagnóstico, 29\% dos casos apresentam-se com tumor restrito aos ovários, $6 \%$ com tumores disseminados regionalmente e 59\% com disseminação à distância (Linasmita9 ${ }^{9}$ et al., 2004).

O tratamento da doença avançada, tanto localmente quanto à distância, baseia-se na quimioterapia. Fármacos derivados da platina (cisplatina e carboplatina) representam hoje a primeira linha de tratamento.Várias substâncias foram associadas aos derivados de platina com o objetivo de aumentar a sobrevida $\left(\right.$ Gruppy $^{10}$ et al., 2005).

Em 2003, Ozols ${ }^{11}$ et al. demonstraram que a associação de paclitaxel com carboplatina apresentava os mesmos resultados que paclitaxel e cisplatina, com a vantagem de causar menor toxicidade e ter maior facilidade de administração. Após este estudo, a associação dos fármacos paclitaxel e carboplatina tornou-se a primeira opção de tratamento do câncer de ovário avançado.

\subsubsection{CÂNCER DE ENDOMÉTRIO}

O câncer de endométrio é o câncer genital mais comum nos países desenvolvidos (Parkin ${ }^{1}$ et al., 2001). Nos Estados Unidos da América é a quarta neoplasia mais freqüente entre as mulheres, com estimativa de 34.000 novos casos diagnosticados e 6.000 óbitos no ano de 1996.

No Brasil, são esperados anualmente 5.685 casos novos de adenocarcinoma de endométrio, com taxa de 7,6/100.000 mulheres, 
variando de 2,0/100.000 na região Norte a 9,9/100.000 na Sudeste. Estimase aumento da incidência nas próximas décadas, decorrente de aumento da longevidade associado à freqüência elevada de alguns fatores de risco, como a obesidade (Diczfalusy $\left.{ }^{12}, 1986\right)$.

No Brasil, é o segundo tumor mais freqüente da pelve feminina. A maior parte das pacientes apresenta doença localizada no útero no momento do diagnóstico, o que permite o tratamento cirúrgico associado ou não à radioterapia (Souen ${ }^{13}$ et al., 2001).

O estadiamento do câncer de endométrio pode ser clínico ou cirúrgico. O estadiamento patológico-cirúrgico adotado em 1988 pela FIGO, levou em consideração vários aspectos não relacionados anteriormente, como o grau histológico, a profundidade de invasão miometrial e os envolvimentos do colo, de vasos, dos linfonodos pélvicos e paraórticos e a citologia peritoneal.

Os casos com doença localmente avançada ou doença recidivante necessitam geralmente de tratamento sistêmico. Entretanto, o número efetivo de agentes quimioterápicos é ainda limitado. Em 1996, o Grupo de Ginecologia Oncológica (GOG) americano descreveu a atividade do fármaco paclitaxel em carcinoma de endométrio (Ball ${ }^{14}$ et al., 1996).

Em 2003, Lincoln ${ }^{15}$ et al. instituíram o uso do paclitaxel em pacientes com doenças persistentes ou recorrentes, refratárias ao tratamento. Os resultados foram promissores, sendo o paclitaxel opção efetiva de terapêutica, mesmo naquelas que fizeram uso prévio de quimioterapia. 


\subsubsection{NOVAS PERSPECTIVAS DE TRATAMENTO} QUIMIOTERÁPICO

Nos tumores malignos onde há proliferação celular acelerada, a necessidade aumentada de colesterol e outros lipídeos para a síntese de membranas celulares pode determinar expressão aumentada de receptores de lipoproteína de baixa densidade (rLDL), conforme descrito por Eriksson ${ }^{16}$ et al., em 1989. Isso permite maior captação de lipoproteína de baixa densidade (LDL) pelas células neoplásicas, fornecendo os lipídeos necessários à duplicação celular. O aumento do número de receptores é fenômeno intenso, podendo superar várias vezes o número de receptores das células normais $\left(\mathrm{Ho}^{17}\right.$ et al., 1978), o que poderia explicar, em parte, as baixas concentrações de colesterol encontradas em várias doenças neoplásicas.

Em 1993, Maranhão ${ }^{18}$ et al. demonstraram que uma nanoemulsão lipídica (LDE) com composição semelhante à da LDL humana, com exceção da parte protéica, ligava-se aos rLDL, sendo captada para o interior das células.

Do que se conhecia sobre o comportamento da LDE, levantou-se a hipótese de que pudesse substituir a variedade natural como veículo para direcionar os fármacos antineoplásicos para os tecidos malignos, evitando órgãos e tecidos normais (Maranhão ${ }^{19}$ et al., 1992; Maranhão ${ }^{20}$ et al., 1994). 


\subsection{LDL E CÂNCER}

\subsubsection{LIPOPROTEÍNAS}

A estrutura básica das lipoproteínas é composta por um centro lipídico apolar (triglicérides e éster de colesterol) revestido por fosfolípides, colesterol livre e apolipoproteínas (Jackson ${ }^{21}$ et al., 1976).

As lipoproteínas, de acordo com as características físicas e a composição química, são classificadas em quatro grandes grupos: os quilomícrons, que são as maiores partículas lipoprotéicas e as menos densas, devido à alta proporção de lípides (até 99\%); a lipoproteína de muito baixa densidade (VLDL), com maior proporção de proteína; a LDL, rica em ésteres de colesterol, e a lipoproteína de alta densidade (HDL), a menor e mais densa das lipoproteínas.

\subsubsection{LIPOPROTEÍNAS DE BAIXA DENSIDADE}

A LDL é uma lipoproteína constituída de um núcleo apolar de ésteres de colesterol e resíduos de triglicérides, estabilizada por uma monocamada de fosfolípides que também contém colesterol livre. É o produto final de degradação da VLDL e tem meia vida de 2 a 3 dias, sendo carreadora de 2/3 do colesterol plasmático total em indivíduos normais (Calvert e $\mathrm{Abbey}^{22}$, 1985). 
A LDL tem como função fisiológica o transporte do colesterol necessário para a síntese de membranas de células em divisão e a de hormônios esteróides no córtex da supra-renal e nas gônadas.

A depuração plasmática de partículas de LDL é mediada essencialmente pelos rLDL. As apoproteínas (apo) promovem estabilidade estrutural para as lipoproteínas e funcionam como ligantes nas interações lipoproteína-receptor ou são co-fatores nos processos enzimáticos que regulam o metabolismo das lipoproteínas. A apo-B100, a única apoproteína da LDL, é a responsável pela ligação da LDL ao seu receptor. O fígado expressa grande número de receptores de LDL e remove cerca de $75 \%$ de toda a LDL do plasma (Dietschy ${ }^{23}$ et al., 1993).

Entretanto, quase todos os tecidos do organismo expressam rLDL. Esses receptores encontram-se em regiões específicas, isto é, depressões da membrana celular denominadas "coated pits", que são revestidos por proteínas denominadas clatrinas. Após a interação das lipoproteínas com os receptores, essa região sofre invaginação, formando vesículas endocíticas. A seguir, o envoltório de clatrina dissocia-se e ocorre a fusão de várias vesículas formando os endossomos. A diminuição do $\mathrm{pH}$ nesses endossomos promove o desligamento do complexo receptor-LDL, com o retorno do receptor à superfície celular. Segue-se a fusão de lisossomos com a vesícula e a degradação dos seus componentes, conforme descrito por Goldstein ${ }^{24}$ et al., em 1979. 


\subsubsection{LIPOPROTEÍNA E CÂNCER}

As primeiras evidências de alterações no metabolismo de lípides em pacientes com câncer datam da metade do século passado. Barclay ${ }^{25}$ et al., já em 1955, mostraram haver diminuição de $\alpha 1$-lipoproteínas plasmáticas em mulheres com carcinoma de mama avançado, quando comparadas a mulheres sem a doença.

Bases e Krakoff ${ }^{26}$, em 1965, demonstraram a presença de baixos níveis plasmáticos de lipoproteínas em pacientes com leucemia em comparação a indivíduos normais.

Em 1972, Nydegger e Butler ${ }^{27}$ evidenciaram a diminuição das lipoproteínas séricas em 122 pacientes com vários tipos de carcinomas, quando comparadas a 186 indivíduos saudáveis.

Outras publicações referiam maior captação de LDL pelas células leucêmicas. Em 1973, Chen ${ }^{28}$ et al. e Philippot ${ }^{29}$ et al., em 1977, compararam células leucêmicas e linfócitos normais de ratos e cobaias com leucemia, respectivamente. De igual modo, $\mathrm{Heininger}^{30}$ et al., em 1976, avaliaram células leucêmicas e linfócitos normais recém extraídos de seres humanos.

Em 1978, $\mathrm{Ho}^{17}$ et al., verificaram haver aumento da atividade de rLDL nas células leucêmicas do sangue periférico de pacientes com leucemia mielóide aguda (LMA), em relação às células mononucleares de indivíduos sadios, o qual poderia ser de 3 a 100 vezes maior. 
$\mathrm{Gal}^{31}$ et al, em 1981, comprovaram que linhagens de células de carcinoma vaginal e cervical e de adenocarcinoma de endométrio expressavam cerca de 15 a 30 vezes mais rLDL do que as de células não neoplásicas de fibroblastos cervicais e de glândulas endometriais.

Vitols $^{32}$ et al., em 1984, estudaram a degradação da LDL radioativa em células tumorais do sangue periférico e da medula óssea de pacientes com diagnóstico recente de leucemia, e comparou-as com a de leucócitos normais. Observaram relação inversamente proporcional entre o nível sérico de colesterol e a taxa de captação da LDL radioativa, mediada por receptores. Puderam verificar, ainda, a presença freqüente de hipocolesterolemia em pacientes leucêmicos.

No ano subseqüente, Vitols ${ }^{33}$ et al. (1985) investigaram o mecanismo responsável por essa relação inversa. Estudaram pacientes com leucemia aguda e demonstraram que havia relação inversa entre a concentração plasmática de LDL e a atividade da doença, ou seja, as menores concentrações de LDL encontravam-se nos pacientes com alta contagem de glóbulos brancos. Durante a quimioterapia, houve correlação entre a elevação dos níveis séricos de LDL e o desaparecimento das células leucêmicas da circulação. Concluiu-se que a hipocolesterolemia estaria provavelmente relacionada com o aumento na atividade dos receptores de LDL nas células tumorais.

A expressão aumentada de rLDL poderia ser explicada pelo fato de que as células neoplásicas, por apresentarem rápida proliferação, exigiriam demanda maior de colesterol e de fosfolípides para a síntese de novas 
membranas celulares. Em tese, essa demanda seria suprida por síntese endógena ou via degradação de lipoproteínas de baixa densidade do plasma, o que explicaria o aumento de rLDL e a hipocolesterolemia encontrada em algumas neoplasias (Budd e Ginsberg ${ }^{34}$, 1986; Henriksson ${ }^{35}$ et al., 1989).

Rudling $^{36}$ et al., em 1990, avaliaram a atividade de captação de LDL em tumores cerebrais primários e metastáticos removidos cirurgicamente, que foram comparados com o tecido normal adjacente. A taxa de ligação da LDL no tecido tumoral apresentou grande variabilidade, mas em todos os casos foi significantemente maior do que no tecido cerebral normal.

Em 1992, foi comparada a captação de LDL marcado radioativamente por células de tumores pulmonares e do tecido pulmonar normal adjacente. A captação pelo tecido tumoral foi até 3 vezes maior quando comparada com o tecido não-tumoral (Vitols ${ }^{37}$ et al., 1992).

Vários pesquisadores demonstraram as alterações no metabolismo lipídico de pacientes com câncer. Alguns mostraram relação entre a diminuição nos níveis de colesterol plasmático e a progressão da doença (Pekkanen $^{38}$ et al., 1992; Iribarren ${ }^{39}$ et al., 1995). Outros verificaram que houve normalização dos níveis plasmáticos de colesterol em pacientes com câncer após tratamento e remissão da doença (Niendorf ${ }^{40}$ et al., 1995). 


\subsubsection{LDL COMO AGENTE DIRECIONADOR DE FÁRMACOS}

A possibilidade de se utilizar a LDL como agente direcionador de fármacos para as células neoplásicas foi estudada por vários grupos (Rudling ${ }^{41}$ et al., 1983; Lundberg $^{42}$, 1987; Samadi-Baboli3 ${ }^{43}$ et al., 1990) e essa utilização estaria baseada em propriedades inerentes à partícula de LDL e do seu receptor. A LDL poderia ser capaz de transportar fármacos lipofílicos que podem ter efeito citotóxico. A internalização do fármaco na LDL protegeria-o contra o ataque de biomoléculas plasmáticas e da água. Além disso, o fármaco incorporado na LDL teria maior concentração nas células neoplásicas, as quais apresentam aumento de expressão de rLDL em relação às normais.

Contudo, a obtenção de LDL humana do soro em altas concentrações é procedimento de alta complexidade, além do risco de transmissão de doenças infecciosas.

A incorporação de um fármaco na partícula também pode resultar na perda da apoB-100 e, conseqüentemente, da capacidade de ligação aos rLDL, além de poder alterar ou até mesmo quebrar a sua estrutura. (Rensen ${ }^{44}$ et al., 1997)

\subsubsection{NANOEMULSÃO LIPÍDICA ARTIFICIAL (LDE)}

Como já se assinalou, Maranhão e Roland ${ }^{45}$ (1993), demonstraram que apesar da LDE não ter proteína, ao ser injetada na circulação 
plasmática, entra em contato com as lipoproteínas naturais, adquire a apo E, que pode ser reconhecida pelo receptor da LDL. A apo $E$ serve para a LDE ligar-se ao receptor, sendo captada pela célula.

Estudos de competição em linfócitos mostraram que a LDL natural compete com LDE pela captação celular, comprovando que a remoção de ambas se dá pelo mesmo receptor específico (Maranhão ${ }^{46}$ et al., 1997).

A partícula artificial LDE tem mais afinidade pelos receptores da LDL do que a própria LDL natural (Hirata ${ }^{47}$ et al., 1999), isto porque o meio ligante ao receptor utilizado pela LDE é a apo E, que tem mais afinidade pelo receptor do que a apo B-100 da LDL natural.

A partir de tais evidências, levantou-se a hipótese de que a LDE pudesse substituir a LDL natural como veículo para direcionar os fármacos antineoplásicos, evitando órgãos e tecidos normais (Maranhão ${ }^{19}$ et al., 1992; Maranhão ${ }^{20}$ et al., 1994). Desse modo, os agentes antineoplásicos seriam incorporados à LDE. Posteriormente, a nanoemulsão seria injetada na circulação, adquiriria a apo $\mathrm{E}$ onde se ligaria, de preferência, aos rLDL das células neoplásicas.

Esta hipótese foi inicialmente comprovada em pacientes com leucemia mielocítica aguda (LMA). Verificou-se que a LDE foi removida com velocidade muito maior nos pacientes com LMA do que nos controles. Em contrapartida, após os pacientes serem tratados com esquemas quimioterápicos convencionais e atingido completa remissão da doença, a remoção plasmática da LDE tornava-se mais lenta, normalizando-se. Isto mostrava que as células de LMA, com receptores em número muito maior, 
provocaram remoção acelerada da nanoemulsão. Quando estas foram destruídas pela quimioterapia, a remoção era normalizada. Neste trabalho, também se demonstrou a captação da LDE pela medula óssea infiltrada de células de LMA de maneira direta, por meio de imagens de Medicina Nuclear obtidas com LDE marcada com Tecnécio ${ }^{99 m}$. Neste experimento, comprovou-se que $70 \%$ da LDE injetada foi captada pelas células leucêmicas (Maranhão ${ }^{20}$ et al., 1994).

Estudos realizados em pacientes com câncer de ovário e mama mostraram que a LDE se concentra mais nos tecidos neoplásicos. Em câncer de ovário, por exemplo, a captação da LDE foi em média 10 vezes maior do que no tecido normal (Ades ${ }^{48}$ et al., 2001), enquanto em carcinoma de mama, a captação tumoral foi 4,5 vezes, em média, maior do que a do tecido mamário normal (Graziani ${ }^{49}$ et al., 2002). Estes experimentos comprovam, portanto, que é possível direcionar um veículo feito artificialmente para o tecido neoplásico.

Posteriormente, foi caracterizada a incorporação da LDE a um quimioterápico de natureza lipofílica, a carmustina. Estudou-se a estabilidade do complexo e a integridade química do fármaco após a administração sistêmica e determinou-se sua biodistribuição e toxicidade em ratos (Maranhão ${ }^{50}$ et al., 2002).

A associação da nanoemulsão com a carmustina não alterou o direcionamento da LDE para os seus sítios de ligação específicos. Através de estudos de incubação com células normais e de linhagens neoplásicas, 
verificou-se que a carmustina, quando associada à LDE, não perdia a sua atividade citotóxica (Maranhão ${ }^{50}$ et al., 2002).

Em um grupo de pacientes com mieloma múltiplo não tratados, foi possível avaliar a ação terapêutica do complexo LDE-carmustina, na dose de $180 \mathrm{mg} / \mathrm{m}^{2}$ de superfície corpórea. Além da nítida melhora clínica de seis pacientes, os níveis de imunoglobulina $M$ secretada pelas células do mieloma decresceram em mais de $60 \%$, sem que tenha havido efeitos colaterais importantes (Hungria ${ }^{51}$ et al., 2004).

Em 2003, Valdulga ${ }^{52}$ et al. avaliaram a associação de etoposide com a LDE quanto à estabilidade físico-química, toxicidade em ratos e atividade citotóxica. Demonstraram ser a associação estável, com preservação da atividade citostática do fármaco, além de baixa toxicidade em animais.

A estabilidade da associação de LDE-etoposide foi também pesquisada em mulheres com de carcinoma de ovário (Azevedo ${ }^{53}$ et al., 2005). Observou-se ser a maior parte da droga mantida nas partículas da nanoemulsão até a remoção da circulação e internalização pelas células. Verificou-se, ainda, maior concentração no tecido ovariano neoplásico do que no tecido normal. 


\subsection{PACLITAXEL}

\subsubsection{HISTÓRICO}

Paclitaxel é o fármaco precursor de uma nova classe de agentes estabilizantes de microtúbulos, os taxanos. A sua descoberta envolveu a investigação de aproximadamente 12.000 compostos naturais pelo Instituto Nacional de Câncer dos Estados Unidos (NCI-USA) em 1963. Neste trabalho, diferentes extratos foram testados contra um painel de tumores experimentais e, no final, apenas aqueles que apresentavam alguma atividade antiproliferativa foram selecionados (Rowinsky ${ }^{54}$ et al., 1990).

O paclitaxel foi extraído, primariamente, no começo dos anos 60 a partir do extrato da casca do teixo do Pacífico, o Taxus brevifolia. A forma pura foi obtida somente em 1969 e, sua estrutura, foi descrita pela primeira vez por Wani ${ }^{55}$ et al., em 1971. Seu desenvolvimento foi, inicialmente, dificultado pelo suprimento limitado da árvore e pela baixa solubilidade da molécula em água, o que, de fato, retardou em muito sua disponibilização para o mercado farmacêutico. Por ser fármaco um de origem vegetal, seu suprimento era escasso. Em meados dos anos 80, a partir do desenvolvimento de um método de produção semi-sintética, passou a ser obtido de um precursor não citotóxico extraído de teixos mais abundantes, como o Taxus baccata (Horwitz $\left.{ }^{56}, 1992\right)$.

$\mathrm{O}$ interesse por este agente cresceu substancialmente quando o $\mathrm{NCl}$ divulgou resultados de experimentos de regressão tumoral onde o paclitaxel 
mostrou ter atividade anti-tumoral bastante significativa (Schiff e Horwitz ${ }^{57}$, 1980).

Tem atividade antineoplásica em carcinoma epitelial de ovário, e em câncer de mama, colo, cabeça, células não-pequenas de pulmão e sarcoma de Kaposi associados com AIDS (Rowinsky $\left.{ }^{58}, 1994\right)$.

O seu mecanismo de ação foi divulgado em 1984 por Manfredi59 et al.. Diferentemente de outros agentes que atuam nos microtúbulos, tais como os alcalóides da vinca, o paclitaxel promove a polimerização da tubulina. Os microtúbulos são essenciais para a manutenção da forma celular, sendo um dos componentes do fuso mitótico e do transporte de organelas dentro das células. A sua ligação aos microtúbulos estimula a polimerização da tubulina, o que, por sua vez, estabiliza os microtúbulos. Dessa forma, o ciclo celular acaba sendo bloqueado em sua última fase, isto é, a G2 e na mitose, o que, por sua vez, impede a divisão celular e a conseqüente proliferação das células neoplásicas $\left(\mathrm{Horwitz}^{56}, 1992\right.$; $\mathrm{Horwitz}^{60}$ et al., 1993).

O mecanismo preciso pelo qual o paclitaxel é transportado para dentro das células é ainda desconhecido. Supõe-se que, devido à sua natureza hidrofóbica, paclitaxel possa entrar na célula por difusão passiva. Esta hipótese é suportada pelos achados de experimentos onde o paclitaxel foi adicionado juntamente com azida sódica sob células em cultura. Esta é responsável pela diminuição do nível de ATP celular e, quando ela é acrescentada ao meio de cultura, a concentração intracelular de paclitaxel não é afetada (Manfredi e Horwitz ${ }^{59}$, 1984). 
A estrutura do paclitaxel consiste em um anel taxano que confere atividade citostática à molécula $\left(W \mathrm{n}^{55}\right.$ et al., 1971) e uma cadeia lateral éstero-específica com dois anéis aromáticos conectados por uma amida. Estudos de ressonância magnética nuclear mostraram que paclitaxel exibe pequeno grau de flexibilidade, dependendo da polaridade do sistema solvente. Em solventes apolares como o clorofórmio, sofre agregação na dependência da sua concentração. Este efeito de agregação está diretamente ligado à formação de pontes de hidrogênio dos quatro grupos funcionais de sua estrutura. Essas ligações podem ser coordenadas, ocorrendo ligações intra e extramoleculares, o que, por seu turno acaba propagando a agregação e provocando a precipitação das moléculas. A tendência de agregação pode contribuir para o seu mecanismo de ação, ou seja, o fármaco estabilizaria os microtúbulos pela formação de pontes associadas entre o fármaco e os microtúbulos (Balasubramanian e Alderfer $\left.{ }^{61}, 1994\right)$.

Sabe-se que o paclitaxel é solúvel em uma variedade de solventes orgânicos incluindo etanol, metanol, benzeno, clorofórmio, entre outros, porém, tais solventes não são administrados em humanos, com exceção do etanol (Trissel $\left.{ }^{62}, 1997\right)$. É praticamente insolúvel em água, com valor aceitável de solubilidade de aproximadamente 0,6 mM (Tarr ${ }^{63}$ et al., 1987). A falta de grupos ionizáveis na molécula não permite que se manipule o $\mathrm{pH}$ com o intuito de aumentar a sua solubilidade.

Para possibilitar a comercialização do paclitaxel pela indústria farmacêutica, efetuou-se a sua solubilização em um sistema de solvente 
utilizado pelo $\mathrm{NCI}$-USA, chamado de diluente 12. Este é composto por partes iguais de etanol e o surfactante Cremophor EL, um derivado poli-oxietilado de óleo de castor. Essa forma comercial foi denominada originalmente de Taxol®.

Um dos maiores problemas associados com a formulação é que o Cremophor EL é tóxico. Embora também seja utilizado para solubilizar outros fármacos, tais como ciclosporina e tenoposide, a quantidade requerida do diluente nestas formulações é inferior à utilizada para solubilizar o paclitaxel (Trissel $\left.{ }^{62}, 1997\right)$. Os efeitos colaterais causados pelo Cremophor EL incluem reações de hipersensibilidade, nefrotoxicidade e neurotoxicidade (Weiss ${ }^{64}$ et al., 1990; Rowinsky ${ }^{65}$ et al., 1989). O Cremophor EL também tem influência na função do endotélio e músculos, causando vasodilatação, dispnéia, letargia e hipotensão (Liebmann ${ }^{66}$ et al., 1993). Com o intuito de se amenizar estes efeitos e de se reduzir a incidência de reações de hipersensibilidade, medidas profiláticas são adotadas durante o tratamento, como o uso de anti-histamínicos e corticosteróides ao longo da infusão (Sharma ${ }^{67}$ et al., 1995).

\subsubsection{NOVAS FORMULAÇÕES E SÍNTESE DE PRÓ-FARMÁCOS}

Tentativas de se retirar o Cremophor EL da formulação, para aumentar o índice terapêutico do paclitaxel, incluem modificações na estrutura da molécula com a finalidade de torná-la hidrossolúvel ou a dissolução do fármaco em outros veículos menos tóxicos. Entre as tentativas 
de se substituir o veículo da formulação, destacam-se a utilização de veículos ou transportadores de menor toxicidade, como as ciclodextrinas (Sharma $^{67}$ et al., 1995), lipossomas (Sharma e Straubinger ${ }^{68}$, 1994; Sharma ${ }^{69}$ et al., 1998), emulsões (Lundberg ${ }^{70}$, 1997; $\operatorname{Kan}^{71}$ et al., 1999), micelas poliméricas (Zhang ${ }^{72}$ et al., 1997), nanopartículas (Cavalli ${ }^{73}$ et al., 2000; Fonseca ${ }^{74}$ et al., 2002; Mu e Feng ${ }^{75}$, 2003) e moléculas conjugadas $\left(\mathrm{Li}^{76}\right.$ et al., 1998).

Existe apenas um relato de associação de paclitaxel à LDL natural na literatura. Nesse estudo ficou demonstrado que a referida associação é extremamente instável no plasma (Masquelier ${ }^{77}$ et al., 2000), com liberação do fármaco nos primeiros minutos após a administração endovenosa.

Para se diminuir a toxicidade do fármaco disponível comercialmente, modificou-a a composição química da sua molécula. Vários autores têm proposto a síntese de derivados do paclitaxel (Deutsch ${ }^{78}$ et al., 1989; Mathew $^{79}$ et al., 1992; Jayasinghe ${ }^{80}$ et al., 1994). Em tese, a introdução de grupos que promovam o aumento de hidrofilicidade da molécula, permitiria a sua solubilização em veículos aquosos, enquanto a introdução de grupos que aumentem a sua lipofilicidade, permitiria que a mesma fosse associada a transportadores de natureza lipídica.

Bons resultados foram obtidos com a modificação química do paclitaxel. Bradley ${ }^{81}$ et al. (2001) acoplaram um ácido graxo natural, o ácido docosahexaenoico (DHA), através de uma ligação éster ao grupo C-2 do paclitaxel. O objetivo era aumentar a atividade farmacológica pelo aumento do tempo de circulação plasmática do fármaco e, conseqüentemente, 
aumento do tempo de exposição ao tumor. DHA-paclitaxel mostrou ser menos tóxico que o paclitaxel, com excepcional propriedade antiproliferativa. No tratamento de pacientes com tumores sólidos obteve-se resposta parcial em 11 de 22 pacientes. Atualmente, estudos de Fase II, com dose cerca de 4,6 vezes maior do que a dose máxima aprovada de paclitaxel, estão em andamento (Harries ${ }^{82}$ et al., 2004).

Em outro estudo, Feng ${ }^{83}$ et al. (2002) sintetizaram uma série de derivados C-2 de paclitaxel através do acoplamento com aminoácidos ligados ao polietilenoglicol. O pró-fármaco resultante mostrou-se mais solúvel do que o paclitaxel, além de apresentar aumento da eficácia antitumoral em modelo animal. Em 2003, Lundberg ${ }^{84}$ et al. observaram melhora nos parâmetros cinéticos e diminuição de toxicidade de um derivado lipofílico do paclitaxel associado a uma emulsão lipídica recoberta com polietilenoglicol.

Rodrigues $^{85}$ et al., em 2005, estudaram a associação LDE-oleato de paclitaxel. A nanoemulsão foi testada em animais e comparada com o fármaco em sua formulação comercial. Com os resultados obtidos, concluíram que a associação LDE-olpaclitaxel apresenta estabilidade tanto "in vitro" como "in vivo". A manutenção da atividade antiproliferativa do fármaco foi confirmada pelo ensaio de citotoxicidade e pela citometria de fluxo. Além disso, a associação mostrou ser menos tóxica do que o fármaco disponível comercialmente e aumentou a sua eficácia no tratamento de um modelo tumoral murino. 
Estes quesitos apresentados anteriormente motivaram a realização de estudos cinéticos em pacientes, a fim de verificar se ocorre a dissociação do complexo LDE-oleato de paclitaxel e se a cinética plasmática é semelhante para os dois componentes. É necessário, ainda, verificar se a associação do fármaco à LDE modifica a propriedade da nanoemulsão de se concentrar nas células neoplásicas com aumento dos receptores, determinando a captação de ambos os componentes nos tecidos acometidos pelo tumor comparativamente ao tecido equivalente normal, como também se a LDE concentra o fármaco no tumor. 


\section{OBJETIVOS}

- Determinar a estabilidade e farmacocinética da associação de LDEoleato de paclitaxel em pacientes com neoplasias malignas do trato genital feminino (colo uterino, endométrio e ovário).

- Comparar a farmacocinética do complexo LDE-oleato de paclitaxel e a composição comercial cristalina em pacientes.

- Comparar a captação da associação de LDE-paclitaxel nos tecidos neoplásico e normal. 


\section{MÉTODOS}

\subsection{CASUÍSTICA}

Oito pacientes voluntárias, com neoplasia maligna do trato genital feminino e com indicação de tratamento cirúrgico, foram selecionadas na enfermaria no Setor de Oncologia Ginecológica da Clínica Ginecológica do Hospital das Clínicas da Faculdade de Medicina da Universidade de São Paulo (HCFMUSP). Foram submetidas ao estudo de cinética plasmática da associação LDE-oleato de paclitaxel ou apenas do fármaco em apresentação comercial. Obteve-se, do grupo de pacientes que recebeu o complexo LDE-oleato de paclitaxel forneceu amostras de material tumoral e de tecido normal correspondente durante o ato cirúrgico. Os tecidos também foram analisados quanto à captação da emulsão.

Todas as pacientes assinaram termo de consentimento (ANEXO A) aprovado pela Comissão de Ética da Instituição, após informação verbal sobre o estudo de que estavam participando.

$\mathrm{Na}$ véspera da cirurgia, coletou-se amostra de sangue para a determinação do perfil lipídico.

Vinte e quatro horas antes do procedimento cirúrgico, as pacientes receberam a emulsão ou o fármaco marcados radioativamente por via intravenosa.

A partir da aplicação, também foram colhidas amostras de sangue, em intervalos pré-determinados, para obtenção da curva de decaimento plasmático da emulsão ou do fármaco, durante 24 horas. 


\subsection{MÉTODOS}

\subsubsection{PREPARO DA EMULSÃO LDE-OLEATO DE PACLITAXEL E APRESENTAÇÃO COMERCIAL DE PACLITAXEL}

3.2.1.1 Preparação da nanoemulsão LDE marcada com $\left[{ }^{14} \mathrm{C}\right]$-oleato de colesterol

Os reagentes utilizados, trioleína e colesterol, foram adquiridos da Nu-Check (Elysian, MN); a fosfatidilcolina e o oleato de colesterol da Lipid Products (Surrey, UK), e o $\left[{ }^{14} \mathrm{C}\right]$-oleato de colesterol da Amershan Internacional (Surrey, UK).

A nanoemulsão LDE foi preparada a partir da mistura de $40 \mathrm{mg}$ de fosfatidilcolina, $20 \mathrm{mg}$ de oleato de colesterol, $1 \mathrm{mg}$ de trioleína e $0,5 \mathrm{mg}$ de colesterol, dissolvidos em clorofórmio/etanol $(2: 1 \mathrm{v} / \mathrm{v})$. Os lípides foram pipetados em frasco de vidro, onde se adicionaram $740 \mathrm{kBq}$ do isótopo $\left[{ }^{14} \mathrm{C}\right]-$ oleato de colesterol. A mistura foi seca sob fluxo de nitrogênio, em banho de água $\left(37^{\circ} \mathrm{C}\right)$, e mantida em dessecador a vácuo, por 16 horas, a $4{ }^{\circ} \mathrm{C}$, para a remoção total dos solventes residuais. Adicionaram-se $10 \mathrm{~mL}$ de solução tampão TRIS-HCl $0,01 \mathrm{M}, \mathrm{pH}$ 8,0. A suspensão de lípides foi emulsificada por irradiação ultrassônica durante 3 horas, sob atmosfera de nitrogênio, com temperatura variando entre 51 e $55{ }^{\circ} \mathrm{C}$. A irradiação ultrassônica foi realizada a 125 watts de potência, em modo contínuo de operação por um disruptor de Branson, modelo B 450 (Arruda Ultrassom, São Paulo, SP), equipado com ponta de titânio com $1 \mathrm{~cm}$ de diâmetro. 
As emulsões foram purificadas por ultracentrifugação (Ultracentrífuga Sorvall, modelo OTD Comb, Wilmington), durante 30 minutos, a $4^{\circ} \mathrm{C}$, a $35.000 \mathrm{rpm}$. O sobrenadante da solução (1 mL), contendo partículas que flotam em densidade de $1,006 \mathrm{~g} / \mathrm{mL}$, foi retirado e descartado. O volume restante foi submetido à nova ultracentrifugação, a 35.000 rpm, durante 2 horas, a $4{ }^{\circ} \mathrm{C}$, após adição de brometo de potássio sólido para ajustar a densidade em 1,21 $\mathrm{g} / \mathrm{mL}$. Do sobrenadante foram removidos $2 \mathrm{~mL}$, os quais contêm a fração das partículas de tamanho e composição desejados.

A nanoemulsão purificada foi dialisada, utilizando-se $4 \mathrm{~mL}$ de solução tampão estéril TRIS-HCl 0,01 M, pH 8,0, e membrana de diálise Spectrapor 6 (Spectrum Medical Ind., LA), por 16 horas, a $4{ }^{\circ} \mathrm{C}$, para a total remoção do brometo de potássio utilizado na etapa final de purificação. A nanoemulsão obtida foi esterilizada por filtração utilizando filtros com poros de $0,2 \mu$ de diâmetro (Maranhão ${ }^{45}$ et al., 1993).

Todo o procedimento de preparo das emulsões foi efetuado em câmara de fluxo laminar vertical, para evitar a contaminação por microorganismos. Essas emulsões foram submetidas a testes de esterilidade na Seção de Bacteriologia do Laboratório do Hospital das Clínicas da Faculdade de Medicina da Universidade de São Paulo e de pirogenicidade "in vivo" no Instituto de Medicina Nuclear da Universidade de São Paulo. 
3.2.1.2 Síntese do $\left[{ }^{3} \mathrm{H}\right]$-oleato de paclitaxel

O oleato de paclitaxel foi sintetizado em duas etapas, a partir de uma adaptação do método de Lundberg ${ }^{86}$ et al. (1987):

Primeira etapa - Preparação do cloreto de oleíla

Foram dissolvidos $378 \mathrm{mg}(1,34 \mathrm{mmol})$ de ácido oléico em diclorometano, aos quais adicionaram-se $35 \mu \mathrm{L}(4,02 \mathrm{mmol})$ de cloreto de oxalila dissolvidos em diclorometano, sob atmosfera de nitrogênio. Secou-se o solvente e o produto foi imediatamente utilizado.

Segunda etapa - Reação entre cloreto de oleíla e paclitaxel

O cloreto de oleíla preparado anteriormente foi dissolvido em $10 \mathrm{~mL}$ de acetonitrila anidra e, à temperatura ambiente, adicionou-se rapidamente sobre esta solução uma mistura de $1 \mathrm{~g}(1,11 \mathrm{mmol})$ de $\left[{ }^{3} \mathrm{H}\right]$-paclitaxel e 32 $\mu \mathrm{L}(3,17 \mathrm{mmol})$ de trietilamina dissolvidos em $50 \mathrm{~mL}$ de acetonitrila anidra. Deixou-se sob agitação por 45 minutos. Lavou-se a fase orgânica com solução de $\mathrm{HCl}$ 0,5N, depois água e, por último, uma solução de cloreto de sódio. O produto foi seco com sulfato de magnésio e filtrado. O solvente foi removido em rotaevaporador. Obteve-se um sólido ligeiramente amarelado, ao qual adicionou-se lentamente uma mistura de 1:10 diclorometano/hexano sob agitação. Obteve-se um precipitado branco, que foi filtrado e lavado com hexano anidro e seco a vácuo. O paclitaxel modificado foi denominado $\left[{ }^{3} \mathrm{H}\right]-$ oleato de paclitaxel. $\mathrm{O} \quad\left[{ }^{3} \mathrm{H}\right]$-paclitaxel foi adquirido da Moravek Radiochemicals (Brea, CA). 
3.2.1.3 Incorporação de $\left[{ }^{3} \mathrm{H}\right]$-oleato de paclitaxel na LDE

O paclitaxel foi associado à LDE numa razão 9:1 em massa de lipídios e fármaco, sendo $1,8 \mathrm{~mL}$ de LDE marcada radioativamente com $\left[{ }^{14} \mathrm{C}\right]$-oleato de colesterol adicionados a $0,2 \mathrm{~mL}$ de solução de $\left[{ }^{3} \mathrm{H}\right]$-oleato de paclitaxel em etanol. A incorporação foi realizada por sonicação por 30 minutos com temperatura variando entre 50 e $55^{\circ} \mathrm{C}$ em banho de água. As preparações foram feitas no mesmo dia dos respectivos experimentos e esterilizadas em filtro Millipore 0,22 $\mu \mathrm{m}$. A associação LDE-fármaco foi designada LDE-oleato de paclitaxel.

3.2.1.4 Preparação da apresentação comercial do paclitaxel

$\mathrm{O}\left[{ }^{3} \mathrm{H}\right]$-paclitaxel foi solubilizado em um sistema de solvente utilizado na formulação comercial, chamado de diluente 12. Este é composto por partes iguais de etanol e o surfactante Cremophor EL, um derivado polioxietilado de óleo de castor. A forma comercial do paclitaxel foi chamada de $\left[{ }^{3} \mathrm{H}\right]$-paclitaxel. 


\subsubsection{DETERMINAÇÃO DA CINÉTICA PLASMÁTICA DA ASSOCIAÇÃO $\left[{ }^{14} \mathrm{C}\right]$-LDE E $\left[{ }^{3} \mathrm{H}\right]$-OLEATO DE PACLITAXEL}

Os estudos do comportamento cinético da associação $\left[{ }^{14} \mathrm{C}\right] \mathrm{LDE}-\left[{ }^{3} \mathrm{H}\right]-$ oleato de paclitaxel foram realizados em tempos pré-determinados durante as $24 \mathrm{~h}$ do protocolo de pesquisa.

Antes do procedimento foram canuladas duas veias de membros superiores diferentes com cateter "butterfly". Foram injetados $2 \mathrm{~mL}$ de $\left[{ }^{3} \mathrm{H}\right]$ oleato de paclitaxel associado à $\left[{ }^{14} C\right]-L D E$ nas pacientes, com a finalidade de estudar a remoção plasmática do componente lipídico oleato de colesterol e do oleato de paclitaxel.

Após a injeção, amostras de sangue $(5 \mathrm{~mL})$ foram coletadas de outro acesso venoso e acondicionadas em tubos de ensaio contendo heparina (50 $\mathrm{Ul} / \mathrm{mL}$ de sangue) nos tempos 5,15 e 30 minutos e 1, 2, 4, 6, 8, 10, 12 e 24 horas. As amostras foram centrifugadas por 15 minutos, a $3000 \mathrm{rpm}$. A radioatividade presente em alíquotas de $1 \mathrm{~mL}$ de plasma em cada um dos tempos de coleta foi medida usando-se $7 \mathrm{~mL}$ de solução cintiladora (PPO:dimethyl-POPOP:Triton X-100:tolueno, $5 \mathrm{~g}: 0,5 \mathrm{~g}: 333 \mathrm{~mL}: 667 \mathrm{~mL}$ ) em contador Beta (Liquid Scintilation Analyser, $1600^{\text {TR }}$ Tri-Carb, PACKARD), com o software Plus Vers. 5.01 da Diamond Computers, para determinação das contagens de ${ }^{14} \mathrm{C}$ e ${ }^{3} \mathrm{H}$ das amostras.

Foram traçadas curvas de remoção plasmática dos componentes radioativos e calculadas as taxas fracionais de remoção (TFR) dos mesmos, com o uso de um "software" desenvolvido para análise de cinética (Mesquita $\left.{ }^{90}, 1994\right)$. 
Os parâmetros farmacocinéticos: tempo de meia vida $\left(t_{1 / 2}\right)$, área sob a curva (AUC), "clearance" plasmático $(\mathrm{Cl})$ e volume de distribuição foram calculados utilizando-se um "software" de modelo multicompartimental (Software PK Solutions, Ashland, $\mathrm{OH}$ ).

\subsubsection{DETERMINAÇÃO DA CINÉTICA PLASMÁTICA DO FÁRMACO [ $\left.{ }^{3} \mathrm{H}\right]-$ PACLITAXEL}

Os estudos do comportamento cinético da apresentação comercial do paclitaxel foram realizados em tempos pré-determinados durante as $24 \mathrm{~h}$ do protocolo de pesquisa.

Como já se referiu anteriormente, antes do procedimento foram canuladas duas veias de membros superiores diferentes com cateter "butterfly". Injetaram-se $6 \mathrm{mg}$ ou $2 \mathrm{~mL}$ de $\left[{ }^{3} \mathrm{H}\right]$-paclitaxel nas pacientes, com a finalidade de estudar a sua remoção plasmática.

Após a injeção, de igual modo, amostras de sangue $(5 \mathrm{~mL})$ foram coletadas da outra veia puncionada e acondicionadas em tubos de ensaio contendo heparina (50 Ul/mL de sangue) nos tempos 5, 15 e 30 minutos e 1 , $2,4,6,8,10,12$ e 24 horas. As amostras foram centrifugadas por 15 minutos, a $3000 \mathrm{rpm}$. A radioatividade presente em alíquotas de $1 \mathrm{~mL}$ de plasma em cada um dos tempos de coleta foi medida utilizando-se $7 \mathrm{~mL}$ de solução cintiladora (PPO:dimethyl-POPOP:Triton X-100:tolueno, $5 \mathrm{~g}:$ 0,5g :

333mL : 667mL) em contador Beta (Liquid Scintilation Analyser, $1600^{\mathrm{TR}}$ TriCarb, PACKARD), com o software Plus Vers. 5.01 da Diamond Computers, para determinação da contagem de ${ }^{3} \mathrm{H}$ das amostras. 
A curva de remoção plasmática do componente radioativo foi traçada e calculou-se a taxa fracional de remoção (TFR) do mesmo, com o uso de um "software" desenvolvido para análise de cinética (Mesquita" ${ }^{90}$ 1994).

Os parâmetros farmacocinéticos: tempo de meia vida $\left(t_{1 / 2}\right)$, área sob a curva (AUC), "clearance" plasmático $(\mathrm{Cl})$ e volume de distribuição foram também calculados utilizando-se um "software" de modelo multicompartimental (Software PK Solutions, Ashland, $\mathrm{OH}$ ).

\subsubsection{PROCEDIMENTO CIRÚRGICO E OBTENÇÃO DOS FRAGMENTOS}

As pacientes que receberam o complexo LDE-oleato de paclitaxel foram submetidas a procedimento cirúrgico. Retiraram fragmentos de tecido neoplásico, evitando-se a periferia do tumor, em decorrência do processo inflamatório local que pode ocorrer ou áreas de necrose tumoral, e também do respectivo tecido normal. Os materiais foram acondicionados em tubos de ensaio estéreis contendo solução fisiológica (cloreto de sódio a 0,9%).

As cirurgias foram efetuadas no Hospital das Clínicas da Faculdade de Medicina da Universidade de São Paulo (HC-FMUSP).

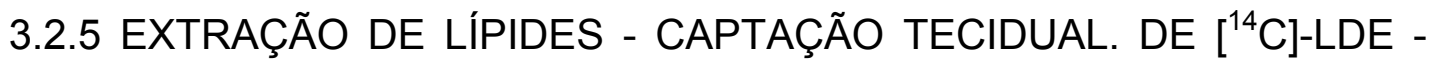
$\left[{ }^{3} \mathrm{H}\right]$ - OLEATO DE PACLITAXEL

Os fragmentos obtidos durante os procedimentos cirúrgicos, depois de adequadamente acondicionados, foram encaminhados imediatamente ao Laboratório de Lípides - Instituto do Coração da FMUSP, onde foi feito o 
procedimento de extração de lípides pelo método de Folch (Folch ${ }^{91}$ et al., 1957).

Os fragmentos foram limpos, em condições adequadas sob placa de gelo, em seguida pesados (mg), e então macerados de modo que ficassem com aspecto pastoso. Posteriormente, foram transferidos para tubos grandes (20x160), adicionados com $10 \mathrm{~mL}$ de metanol e $20 \mathrm{~mL}$ de clorofórmio e deixados em repouso "overnight" a $4{ }^{\circ} \mathrm{C}$.

As amostras foram filtradas, lavadas com 2,5 mL de clorofórmio (2x) e adicionadas com $7 \mathrm{~mL}$ de água bidestilada. A fase sobrenadante foi aspirada a vácuo e descartada. Adicionaram-se $4 \mathrm{~mL}$ de "Clear Folch" $\left(\mathrm{CHCl}_{3} / \mathrm{MEOH} / \mathrm{H}_{2} \mathrm{O}\right.$, na proporção de 3:48:47); deixados mais uma vez em repouso "overnight" à temperatura ambiente e, novamente, o sobrenadante foi descartado. Em seguida, as amostras foram secas sob fluxo de nitrogênio $\left(\mathrm{N}_{2}\right)$, dissolvidas em solução de Folch e transferidas para tubos menores, lavadas várias vezes, agitando-se o tubo de extração e mais uma vez seca sob fluxo de nitrogênio e reconstituída em $500 \mu \mathrm{L}$ de solução de Folch em gelo.

Os componentes marcados da associação LDE-oleato de paclitaxel foram separados por cromatografia em camada delgada (CCD) em placa de silicagel $60 \mathrm{H}$ (Sigma S-6628), onde foram aplicados $100 \mu \mathrm{L}$ de amostra. Hexano/éter etílico/ácido acético, na proporção 70:30:1, sendo utilizada como fase móvel. As placas foram reveladas com iodo sublimado, demonstrando as áreas das bandas referentes à fração lipídica e ao oleato de paclitaxel. As faixas correspondentes às bandas de interesse foram 
removidas para frascos de cintilação e adicionados $7 \mathrm{~mL}$ de solução cintiladora para análise.

\subsubsection{DETERMINAÇÕES BIOQUÍMICAS SÉRICAS}

Foram determinados, antes da administração do LDE-oleato de paclitaxel, os seguintes parâmetros bioquímicos: colesterol total (CT) e frações (VLDL, LDL e HDL) e triglicérides (TG), em amostras de soro obtidas após 12 horas de jejum, pelos métodos de Siedel ${ }^{87}$ et al. (1983).

As determinações dos triglicérides e colesterol total foram processadas pelo método colorimétrico, utilizando-se, respectivamente, os kits comerciais GPO/PAP e o Colesterol CHOP-PAP (ambos Roche ${ }^{\circledR}$ ). Adotaram-se os valores de referência para adultos consoante as Diretrizes Brasileiras sobre Dislipidemias da Sociedade Brasileira de Cardiologia ${ }^{88}$ (2001).

Os valores normais ou limítrofes de referência para o colesterol total foi menor ou igual a $239 \mathrm{mg} / \mathrm{dL}$, e para os triglicérides foram menores ou iguais a $199 \mathrm{mg} / \mathrm{dL}$.

A medida do colesterol da HDL realizou-se pela precipitação das lipoproteínas que continham a apolipoproteína B (LDL e VLDL) do plasma total, com a adição do reativo ácido fosfotúngstico e dos íons de magnésio, seguidos da centrifugação do plasma a 3500 rotações por minuto (rpm), durante um quarto de hora, momento em que se obtinha a HDL no sobrenadante. Esta avaliação foi feita por método enzimático utilizando-se o 
kit CHOP-PAP (Roche $\left.{ }^{\circledR}\right)$, cujo valor de normalidade é maior ou igual a 40 $\mathrm{mg} / \mathrm{dL}$.

A determinação da fração do colesterol LDL foi obtida através da aplicação da fórmula de Friedewald ${ }^{89}$ et al. (1972):

$\mathrm{LDL}=$ colesterol total - (triglicérides $/ 5+\mathrm{HDL})$.

O valor considerado normal ou limítrofe da LDL foi inferior ou igual a $159 \mathrm{mg} / \mathrm{dL}$.

O valor da VLDL foi obtido através da divisão dos triglicérides por cinco, quando estes eram inferiores a $400 \mathrm{mg} / \mathrm{dL}$, como aconteceu em todos os casos analisados. O valor considerado normal da VLDL foi menor que 30 $\mathrm{mg} / \mathrm{dL}$.

Os valores de colesterol total e suas frações e, de triglicérides estão apresentados no ANEXO B e na Tabela1. 
Tabela 1. Idade e perfil lipídico $(\mathrm{mg} / \mathrm{dL})$ das pacientes estudadas: LDEoleato de paclitaxel e paclitaxel comercial. Dados expressos como média \pm desvio-padrão.

\begin{tabular}{|c|c|c|}
\hline & Grupos & \\
\hline & LDE-Oleato de paclitaxel $(n=5)$ & Paclitaxel $(n=3)$ \\
\hline Idade (anos) & $61 \pm 15,6$ & $39 \pm 10,6$ \\
\hline Colesterol total (mg/dL) & $198 \pm 47$ & $239 \pm 42$ \\
\hline LDL (mg/dL) & $124 \pm 40$ & $140 \pm 42$ \\
\hline $\mathrm{HDL}(\mathrm{mg} / \mathrm{dL})$ & $44 \pm 7$ & $60 \pm 12$ \\
\hline $\operatorname{VLDL}(\mathrm{mg} / \mathrm{dL})$ & $30 \pm 9$ & $39 \pm 10$ \\
\hline Triglicérides (mg/dL) & $153 \pm 45$ & $193 \pm 46$ \\
\hline
\end{tabular}

\subsection{ANÁLISE ESTATÍSTICA}

Para a análise dos dados com distribuição não paramétrica, utilizouse o teste de Mann-Whitney. Quando a distribuição dos dados foi paramétrica, empregou-se o test t de "Student".

Todos os valores foram expressos por média \pm desvio padrão (d.p.), considerando-se como nível crítico para significância valores de $p \leq 0,05$. 


\section{RESULTADOS}

4.1 CINÉTICA DOS COMPONENTES MARCADOS RADIOATIVAMENTE: $\left[{ }^{14} \mathrm{C}\right]-\quad$ LDE, $\left[{ }^{3} \mathrm{H}\right]-O L E A T O \quad$ DE PACLITAXEL E APRESENTAÇÃO COMERCIAL $\left[{ }^{3} \mathrm{H}\right]-$ PACLITAXEL (ANEXO C)

A Figura 1 mostra as curvas de remoção plasmática do $\left[{ }^{14} \mathrm{C}\right]$-oleato de colesterol e do [ $\left.{ }^{3} \mathrm{H}\right]$-oleato de paclitaxel após a injeção de LDE-oleato de paclitaxel em cinco pacientes. Ambas as curvas demonstram um padrão biexponencial, sendo que a do LDE-oleato de colesterol é paralela à do LDEoelato de paclitaxel. A partir delas calculou-se a taxa de remoção plasmática da $\operatorname{LDE}(0,092 \pm 0,039)$ e do oleato de paclitaxel $(0,069 \pm 0,027)$; não houve diferença estatística entre elas $(p=0,390)$. 


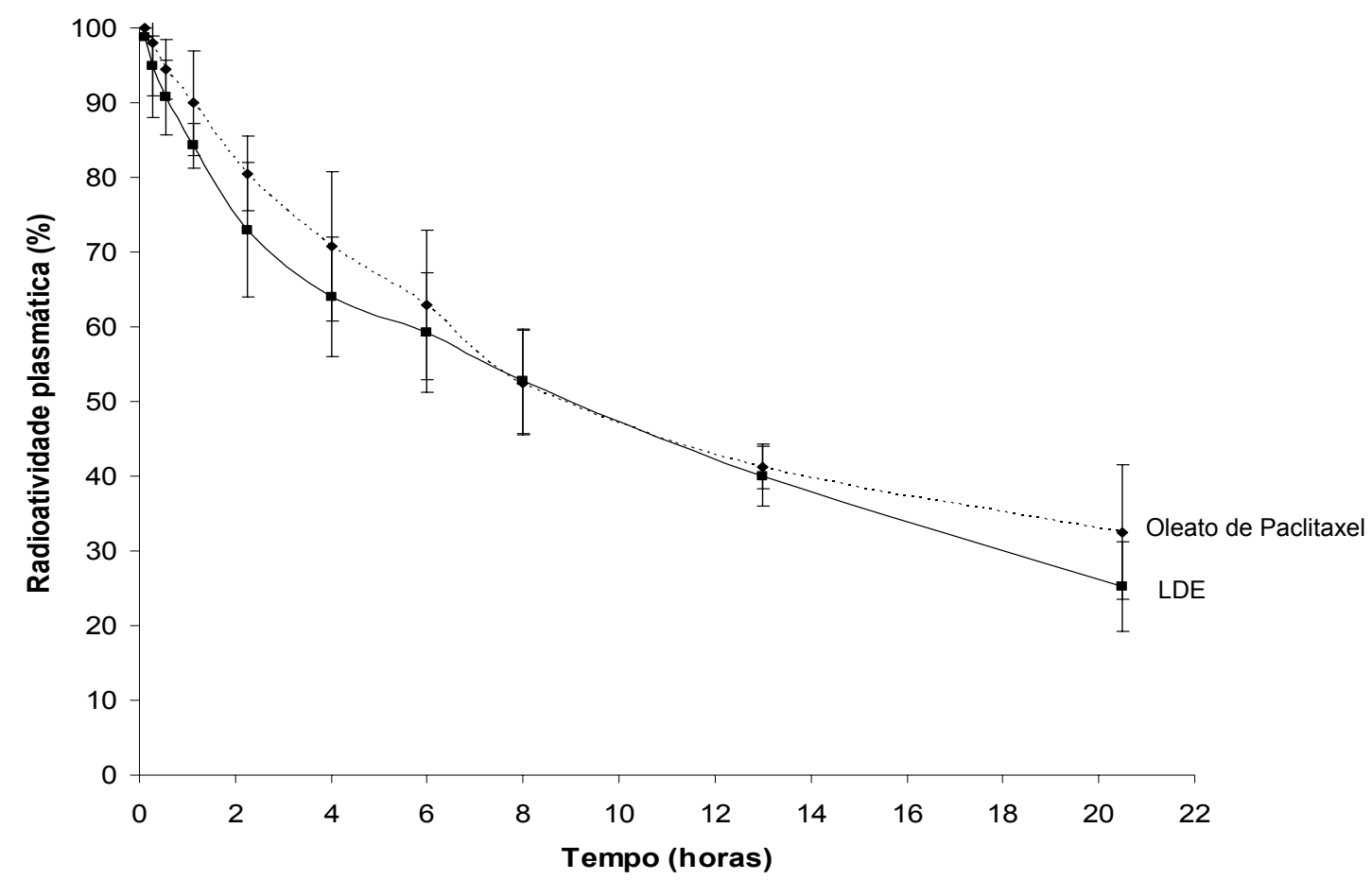

Figura 1. Decaimento plasmático de $\left[{ }^{3} \mathrm{H}\right]$-oleato de paclitaxel $(\bullet)$ associado ao $\left[{ }^{14} \mathrm{C}\right]$-oleato de colesterol-LDE $(\boldsymbol{\square})$ injetados por via endovenosa em cinco pacientes. Amostras de plasma foram coletadas durante 24 horas após a administração. Os resultados estão expressos em média \pm desvio padrão.

A Figura 2 desvela as curvas de remoção plasmática do $\left[{ }^{3} \mathrm{H}\right]$-oleato de paclitaxel associado à LDE ministrada em cinco pacientes e a formulação comercial do $\left[{ }^{3} \mathrm{H}\right]$-paclitaxel em outras três pacientes. Ambas as curvas demonstram um padrão biexponencial. Como se vê, a queda da concentração plasmática da curva do oleato de paclitaxel é mais lenta do que a do paclitaxel comercial. A taxa de remoção plasmática da LDE- 
paclitaxel $(0,069 \pm 0,027)$ foi menor que a observada para o paclitaxel comercial $(0,231 \pm 0,128)$. Houve diferença estatística entre as taxas $(p=$ 0,028).

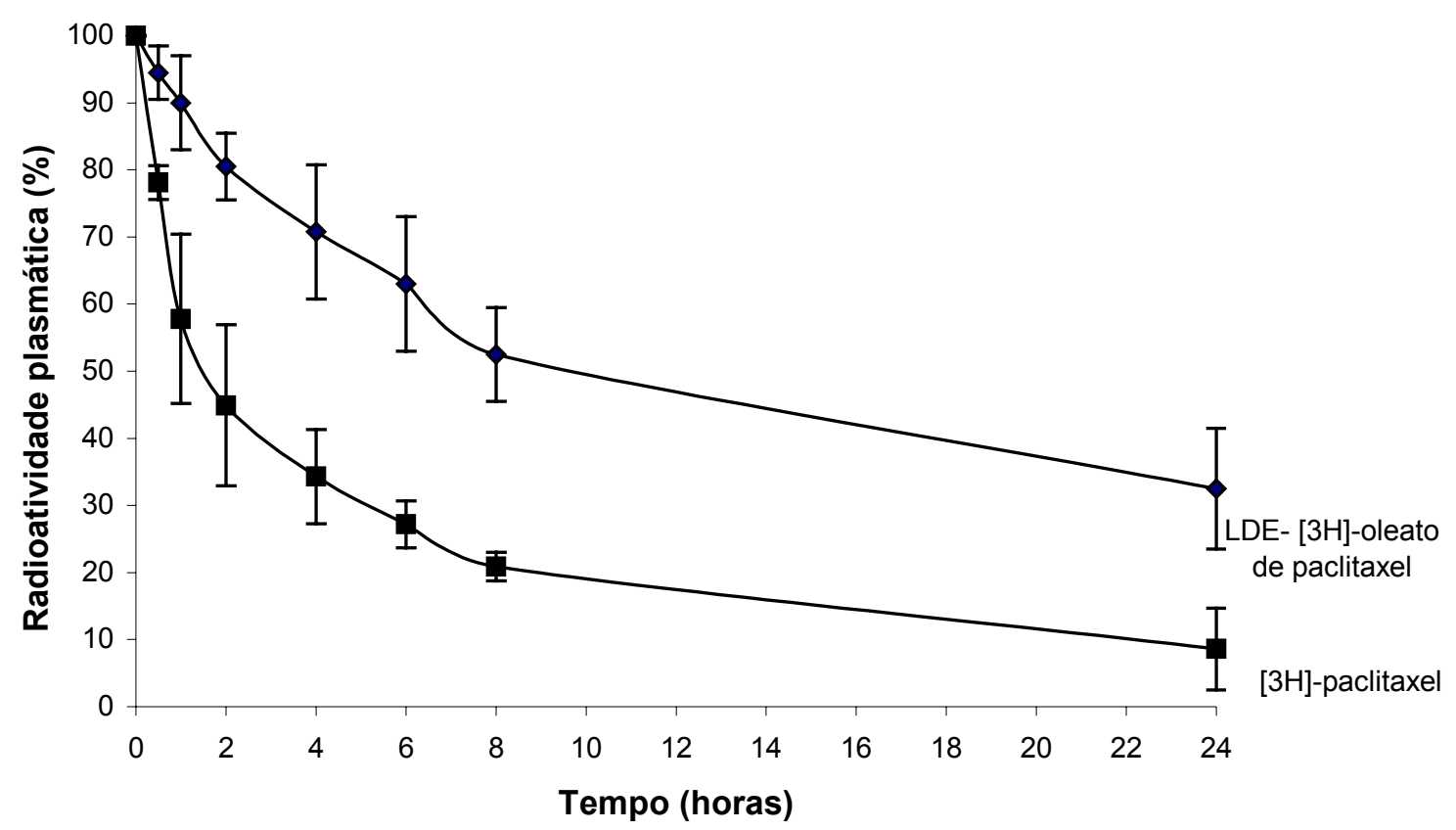

Figura 2. Decaimento plasmático de LDE-[3H]-oleato de paclitaxel (•) injetado por via endovenosa em cinco pacientes. Decaimento plasmático do $\left[{ }^{3} \mathrm{H}\right]$-paclitaxel comercial $(\boldsymbol{\square})$ em três pacientes. Amostras de plasma foram coletadas durante 24 horas após a administração. Os resultados estão expressos em média \pm desvio padrão. 
Os parâmetros farmacocinéticos: tempo de meia vida ( $\left.T_{1 / 2}\right)$, "clearance" plasmático $(\mathrm{CI})$, área sob a curva $(\mathrm{AUC})$ e volume de distribuição $\left(V_{\text {ss }}\right)$ estão representados nas Tabelas 2 e 3 , referentes ao oleato de paclitaxel e ao paclitaxel comercial, respectivamente. Tanto a meia vida $(14,51 \pm 3,23 \mathrm{~h})$ como a AUC $(2,49 \pm 0,35 \mathrm{ng} / \mathrm{h} / \mathrm{L})$ do oleato de paclitaxel foram maiores do que as respectivas medidas do paclitaxel comercial $\left(T_{1 / 2}=\right.$ $6,62 \pm 2,05 \mathrm{~h}$ e $\mathrm{AUC}=2,49 \pm 0,35 \mathrm{ng} / \mathrm{h} / \mathrm{L})$, com $\mathrm{p}=0,0097$ e 0,0038, respectivamente. Entretanto, o $\mathrm{V}_{\mathrm{ss}}$ e $\mathrm{O} \mathrm{CL}$ não variaram significativamente $(p=0,6186$ e 0,0926$)$.

Tabela 2. Parâmetros farmacocinéticos do oleato de paclitaxel após a infusão de $\left[{ }^{3} \mathrm{H}\right]$ - oleato de paclitaxel associado à LDE

Parâmetros farmacocinéticos do $\left[{ }^{3} \mathrm{H}\right]$-oleato de paclitaxel

\begin{tabular}{cccccc}
\hline Patiente (№) & $\mathrm{T}_{1 / 2}(\mathrm{~h})$ & AUC ng/h/L & Vss (L) & $\mathrm{Cl}(\mathrm{L} / \mathrm{h})$ & $\mathrm{FCR}\left(\mathrm{h}^{-1}\right)$ \\
\hline 1 & 17,16 & 2,32 & 31,98 & 1,29 & 0,067 \\
2 & 8,13 & 3,32 & 17,65 & 1,50 & 0,088 \\
3 & 12,81 & 2,24 & 41,33 & 2,24 & 0,045 \\
4 & 17,95 & 2,53 & 79,46 & 3,07 & 0,098 \\
5 & 16,48 & 2,02 & 35,27 & 1,48 & 0,046 \\
\hline & $14,51 \pm 3,23$ & $2,49 \pm 0,35$ & $41,14 \pm 15,41$ & $1,92 \pm 0,59$ & $0,069 \pm 0,027$ \\
\hline Média \pm d.p. & & & & &
\end{tabular}


Tabela 3. Parâmetros farmacocinéticos do paclitaxel comercial após a infusão de $\left[{ }^{3} \mathrm{H}\right]$-paclitaxel

\begin{tabular}{cccccc}
\hline \multicolumn{6}{c}{ Parâmetros farmacocinéticos do $\left[{ }^{3} \mathrm{H}\right]$-paclitaxel } \\
\hline Paciente (№) & $\mathrm{T}_{1 / 2}(\mathrm{~h})$ & AUC ng/h/L & Vss (L) & $\mathrm{Cl}(\mathrm{L} / \mathrm{h})$ & $\mathrm{FCR}\left(\mathrm{h}^{-1}\right)$ \\
\hline 1 & 8,96 & 1,50 & 42,95 & 3,32 & 0,097 \\
2 & 5,11 & 0,80 & 45,56 & 6,18 & 0,247 \\
3 & 5,80 & 1,47 & 17,05 & 2,03 & 0,350 \\
\hline Média \pm d.p. & $6,62 \pm 2,05$ & $1,26 \pm 0,40$ & $35,19 \pm 15,76$ & $3,84 \pm 2,12$ & $0,23 \pm 0,13$ \\
\hline d.p. - desvio padrão & & & &
\end{tabular}

\subsection{EXTRAÇÃO DE LÍPIDES - CAPTAÇÃO TECIDUAL DE $\left[{ }^{14} \mathrm{C}\right]-\mathrm{LDE} X\left[{ }^{3} \mathrm{H}\right]-$ OLEATO DE PACLITAXEL}

A Tabela 4 revela o sítio tumoral das pacientes estudadas, os resultados de captação da LDE e do oleato de paclitaxel nos tecido normal e tumoral, bem como a relação entre a captação tecidual da LDE e do fármaco entre esses tecidos. Não houve diferença na percentagem de captação entre LDE e o fármaco, independente do tecido analisado $(p=0,9025)$. Os resultados mostram que tanto a LDE como o fármaco concentram-se mais no tecido tumoral do que no respectivo tecido normal. 
Tabela 4. Captação de LDE e oleato de paclitaxel radioativos pelo tecido normal e tumoral, e seus respectivos sítios tumorais

\begin{tabular}{|c|c|c|c|c|c|c|c|}
\hline \multirow{3}{*}{ Paciente (№) } & \multirow{3}{*}{ Sítio tumoral } & \multirow{2}{*}{\multicolumn{3}{|c|}{$\begin{array}{l}\text { Captação de }\left[{ }^{14} \mathrm{C}\right]-\text { LDE pelo tecido } \\
\qquad(\mathrm{cpm} / \mathrm{g})\end{array}$}} & \multirow{2}{*}{\multicolumn{3}{|c|}{$\begin{array}{l}\text { Captação de }\left[{ }^{3} \mathrm{H}\right] \text { - oleato de paclitaxel pelo tecido } \\
\qquad(\mathrm{cpm} / \mathrm{g})\end{array}$}} \\
\hline & & & & & & & \\
\hline & & Tumor & Normal & Tumor / normal & Tumor & Normal & Tumor / normal \\
\hline 1 & Ovário & 1997 & 348 & 5,71 & 4563 & 941 & 4,85 \\
\hline 2 & Cérvix & 695 & 234 & 2,97 & 2929 & 603 & 4,86 \\
\hline 3 & Ovário & 507 & 353 & 1,43 & 394 & 236 & 1,67 \\
\hline 4 & Endométrio & 264 & 53 & 4,47 & 198 & 33 & 5,82 \\
\hline 5 & Endométrio & 1246 & 459 & 2,71 & 347 & 315 & 1,10 \\
\hline$M \pm$ D.P. & & $942 \pm 692$ & $290 \pm 154$ & $3,5 \pm 1,7^{*}$ & $1686 \pm 1968$ & $426 \pm 353$ & $3,6 \pm 2,1^{*}$ \\
\hline
\end{tabular}

${ }^{*} p=0,9025$ 


\section{DISCUSSÃO}

A investigação do uso da LDE como direcionador de agentes antineoplásicos às células tumorais foi proposta, inicialmente, após a confirmação de a mesma se concentrava de preferência em tecidos neoplásicos (Maranhão ${ }^{20}$ et al., 1994). Imaginando-se uma situação ideal, do ponto de vista estratégico para o direcionamento de quimioterápicos às células tumorais, um fármaco associado à emulsão deveria permanecer ligado de maneira estável, vindo a exercer sua ação citotóxica somente após a sua captação.

O agente antineoplásico paclitaxel é um fármaco hidrofóbico que possui a propriedade de auto-agregação e conseqüente precipitação dependendo do meio e da concentração utilizados (Balasubramanian e Alderfer ${ }^{61}$, 1994). A baixa solubilidade em veículos aquosos resultou na sua dispersão em um veículo pouco tolerado, uma mistura de Cremophor EL e etanol. Por esta razão, a substituição por um veículo que, além de ser bem tolerado, tivesse a propriedade de direcioná-lo às células neoplásicas constituí alternativa atraente.

Demonstrou-se, neste estudo, que a associação LDE-oleato de paclitaxel permanece estável após a infusão endovenosa em pacientes com tumores ginecológicos malignos. Foram observadas alterações nas propriedades farmacocinéticas da nanoemulsão, quando comparadas com a formulação comercial do paclitaxel. As concentrações da LDE e do oleato de paclitaxel nos tecidos tumorais achavam-se aumentadas cerca de 3,5 vezes em relação aos tecidos normais. 
A estabilidade do complexo LDE-paclitaxel é fator indispensável para ser utilizado como carreador específico de fármaco. Uma das propriedades exigidas para que uma substância se associe, de forma estável, à LDE é que seja altamente lipofílico. Recentemente, quimioterápicos de maior lipossolubilidade, como a carmustina ou o etoposide oléico, modificados quimicamente para adquirir esta propriedade, foram associados à LDE, ambos apresentando estabilidades satisfatórias (Maranhão ${ }^{50}$ et al., 2002; Valduga $^{52}$ et al., 2003 ).

Rodrigues $^{85}$ et al, em 2005 , demonstraram que o oleato de paclitaxel permaneceu associado ao LDE quando injetado em modelo animal de melanoma B16. No presente estudo, estes dados experimentais foram por nós confirmados em mulheres portadoras de câncer ginecológico.

Neste sentido, a análise comparativa entre as curvas de decaimento plasmático da nanoemulsão marcada radiativamente e do fármaco associado à LDE mostrou que existe semelhança entre a cinética de ambos os componentes e não houve diferença significativa entre as taxas fracionais de remoção $(p=0,390)$. Tais dados sugerem que a associação do fármaco com a LDE persiste estável até o sítio de ação.

A propósito, Maranhão ${ }^{50}$ et al (2002) demonstraram que o preparado LDE-carmustina é estável. Ensaios realizados em cultura de células comprovaram que a atividade citostática do fármaco se mantém. A biodistribuição em camundongos e a cinética plasmática em pacientes que receberam LDE-carmustina não se alteraram pelo procedimento de associação. Além disso, a captação celular dessa associação ocorreu através 
dos rLDL. A captação tecidual do complexo em tumores malignos de ovário e mama era maior do que no tecido normal. Estudo clínico em pacientes com mieloma múltiplo, com altas doses do complexo, não houve efeitos adversos significativos.

Azevedo $^{53}$ et al, em 2005, verificaram propriedades farmacocinéticas similares ao estudarem o complexo LDE-fármaco em pacientes com carcinoma de ovário, utilizando o oleato de etoposide.

Portanto, os estudos já realizados utilizando a LDE como veículo direcionador de fármacos permite concluir que a nanoemulsão é bastante flexível e pode ser associada a diversos agentes antineoplásicos, permitindo que se faça a quimioterapia combinada.

Apesar da estabilidade da associação LDE-paclitaxel, é necessário comprovar que a adição da droga à nanoemulsão não danifica as propriedades biológicas da LDE, especialmente a habilidade de internalização do complexo LDE-fármaco pelas células através dos rLDL.

Estudos anteriores em que a captação da LDE pelos tecidos tumorais, onde os rLDL estão superexpressos, foi comparada com a dos tecidos normais, embasam a suposição de que o oleato de paclitaxel mantem a propriedade da nanoemulsão em ligar-se aos rLDL, concentrando-se até 3,6 vezes mais no tumor do que no o tecido normal (Ades ${ }^{48}$ et al, 2001; Graziani $^{49}$ et al, 2002).

A internalização celular do complexo LDE-fármaco através do rLDL foi confirmada anteriormente, in vitro (Maranhão ${ }^{50}$ et al, 2002) e in vivo, durante estudo em modelo animal de melanoma B16 (Rodrigues ${ }^{85}$ et al, 2005). 
$\operatorname{Ades}^{48}$ et al, em 2002, avaliaram a captação da LDE marcada radioativamente pelos tecidos ovarianos normal e tumoral em pacientes com neoplasias ovarianas. A concentração da nanoemulsão pelo carcinoma de ovário era, em média, 8 vezes maior em comparação ao ovário contralateral normal.

No presente estudo, a LDE concentrou-se 3,5 vezes mais no tecido tumoral do que no respectivo tecido normal. Esse resultado satisfatório é relevante, porém, inferior ao obtido anteriormente em pacientes com carcinoma de ovário apenas. Entretanto, o estudo atual não incluiu apenas um sítio tumoral: duas pacientes tinham carcinoma de endométrio e outra carcinoma de colo uterino, e apenas duas possuíam carcinoma ovariano. Nesses dois exemplos, a relação de captação do tecido tumoral/normal foi muito diferente: 1,4 e 5,7 .

$\operatorname{Ades}^{48}$ et al, em 2002, observaram ser a relação de captação muito variável, de 2,9 a 27 vezes. Conseqüentemente, a menor captação por nós encontrada pode ser atribuída às diferentes expressões de receptores de LDL não somente entre neoplasias de órgãos distintos, mas também entre os diferentes tipos histológicos de tumores que acometem um mesmo órgão.

Demonstrou-se, também, que a LDE funcionou como veículo carreador de fármaco já que a concentração da nanoemulsão associada ao paclitaxel foi 3,6 vezes maior no tecido tumoral em relação ao normal. Tal resultado foi praticamente igual à concentração de 3,5 vezes da LDE marcada radioativamente. Estes achados coincidem com o comportamento similar das curvas de cinética plasmática da LDE e do complexo LDE-paclitaxel. Esses 
dados demonstram que a LDE carreia o fármaco no plasma e que ambos se concentram no tumor sem haver dissociação significativa.

Outro dado importante a ser corroborado é que a modificação e a associação do paclitaxel à LDE propiciaram um perfil farmacocinético distinto daquele do paclitaxel comercial. O oleato de paclitaxel associado à LDE apresenta tempo de meia vida mais longo e maior área sob a curva comparativamente à apresentação comercial. Isto sugere que uma mesma dose de paclitaxel associado à nanoemulsão se mantém em maiores concentrações plasmáticas durante período maior de tempo.

Como a citotoxicidade do paclitaxel depende da duração da exposição das células ao fármaco (Goble e Bear ${ }^{92}, 2003$ ), a maior meia vida do complexo poderia ser uma vantagem adicional. Seidman ${ }^{93}$ et al. (1996) propuseram que a exposição prolongada a baixas concentrações de paclitaxel poderia promover atividade antitumoral ampliada, já que pacientes resistentes ao fármaco em esquemas tradicionais responderam ao tratamento com infusão contínua por 96 horas. A farmacocinética obtida do complexo LDE-paclitaxel poderia ampliar o espectro farmacológico de ação.

O paclitaxel tem sido utilizado no tratamento de diversas neoplasias ginecológicas malignas, tanto como droga de primeira linha (exemplo: carcinoma de ovário), ou como tratamento alternativo. O seu uso em carcinoma cervical localmente avançado associado à carboplatina como agente radiosensibilizante, comparado com carboplatina isolada, foi melhor tolerado (Rao ${ }^{94}$ et al, 2005). Outrossim, o paclitaxel isolado ou associado a outros agentes antineoplásicos constituem opções aceitas para o tratamento 
de carcinoma de endométrio recidivado ou refratário à quimioterapia prévia (Lincoln ${ }^{15}$ et al, 2003, e Woo ${ }^{95}$ et al, 1996).

Além disso, estudos prévios demonstraram que, em cobaias, a toxicidade do oleato de paclitaxel é nitidamente menor do que a apresentação comercial.

Nossos achados indicam que o complexo LDE-paclitaxel se concentra mais no tumor do que no tecido normal. Tais dados reforçam a necessidade de futuros estudos clínicos para confirmar as vantagens do uso do oleato de paclitaxel no tratamento de neoplasias ginecológicas malignas. 


\section{CONCLUSÕES}

1. O complexo LDE-paclitaxel manteve-se estável na circulação plasmática de pacientes com neoplasias malignas do trato genital feminino, pois se concentrou de forma semelhante tanto no tecido normal quanto no neoplásico.

2. A cinética plasmática realizada nessas pacientes revelou que ambos os componentes marcados radioativamente, LDE e oleato de paclitaxel, tiveram velocidade de remoção plasmática semelhante, indicando, portanto, que o fármaco acompanha a partícula de microemulsão.

3. O perfil farmacocinético da nanoemulsão associada ao oleato de paclitaxel é distinto daquele observado apenas com o paclitaxel comercial, pois, o complexo LDE-oleato de paclitaxel apresentou maior tempo na circulação.

4. A captação da associação LDE-oleato de paclitaxel pelos tecidos tumorais foi, em média, 3,5 vezes maior do que no tecido normal. 
7 ANEXOS

\subsection{ANEXO A}

TERMO DE CONSENTIMENTO LIVRE E ESCLARECIDO

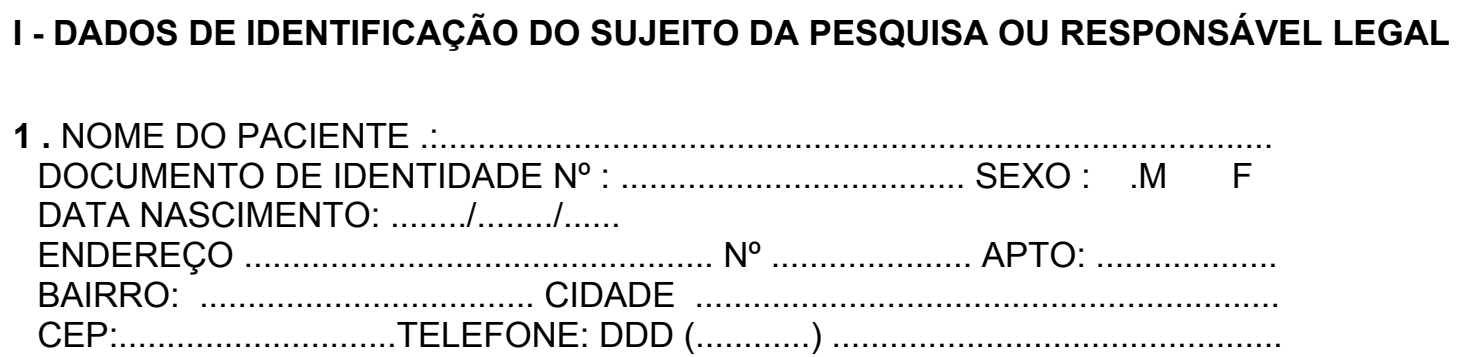

2. RESPONSÁVEL LEGAL

NATUREZA (grau de parentesco, tutor, curador etc.)

DOCUMENTO DE IDENTIDADE N ${ }^{\circ}$ : SEXO: $\mathrm{M} \quad \mathrm{F}$

DATA NASCIMENTO.: ....................

ENDEREÇO: CIDADE: $\mathrm{N}^{\mathrm{O}}$ APTO:

BAIRRO: CEP: TELEFONE: DDD

\section{II - DADOS SOBRE A PESQUISA CIENTÍFICA}

1. TÍTULO DO PROTOCOLO DE PESQUISA : Utilização de uma microemulsão lipídica sem proteínas semelhante à estrutura da LDL para veicular quimioterápicos em neoplasias do trato genital feminino

2. PESQUISADOR: Jesus Paula Carvalho

CARGO/FUNÇÃO: Professor Associado

INSCRIÇÃO CONSELHO REGIONAL Nº 35885

UNIDADE DO HCFMUSP: .Disciplina de Ginecologia HCFMUSP

3. AVALIAÇÃO DO RISCO DA PESQUISA:

$\begin{array}{lll}\text { SEM RISCO } & \text { RISCO MÍNIMO } & \text { RISCO MÉDIO } \\ & \text { RISCO BAIXO } X & \text { RISCO MAIOR }\end{array}$

(probabilidade de que o indivíduo sofra algum dano como conseqüência imediata ou tardia do estudo)

4.DURAÇÃO DA PESQUISA : aproximadamente 24 meses 


\section{III - REGISTRO DAS EXPLICAÇÕES DO PESQUISADOR AO PACIENTE OU SEU REPRESENTANTE LEGAL SOBRE A PESQUISA CONSIGNANDO:}

1. Justificativa e os objetivos da pesquisa - A senhora tem câncer no trato genital feminino (ovário, colo ou corpo uterino). O objetivo desta pesquisa é avaliar o comportamento no sangue e no tumor de um tipo de "colesterol" (chamaremos de LDE) - que é uma gordura no sangue que existe normalmente no seu corpo. Este colesterol será associado ao medicamento "Paclitaxel" - este é um medicamento para tratamento do câncer. Dentro da LDE é colocado o paclitaxel, e como o tumor capta mais LDE que os outros órgãos, o paclitaxel será concentrado em maior quantidade no local do tumor. Este procedimento não alterará ou substituirá o tratamento do câncer, que no seu caso é cirúrgico.

2. Procedimentos que serão utilizados e propósitos, incluindo a identificação dos procedimentos que são experimentais - Um dia antes da cirurgia a senhora terá uma veia puncionada, ou seja, o médico colocará uma agulha na sua veia e injetará a emulsão de colesterol (LDE) com paclitaxel. Esta veia permanecerá puncionada por 24 horas, e através dela serão realizadas coletas consecutivas de sangue. Durante a cirurgia um pequeno fragmento do seu tumor e de tecido normal serão também avaliados.

3. Desconfortos e riscos esperados - A injeção da emulsão não dói, apenas a senhora sentirá uma picada. A senhora poderá sentir um pequeno desconforto quando o médico for puncionar a veia. Após ou durante o procedimento a senhora sentirá um desconforto mínimo por causa da veia que ficará puncionada durante o estudo. A sua cirurgia não sofrerá nenhuma mudança em relação ao proposto anteriormente. A possibilidade de inchaço ou vermelhidão no seu braço é muito pequena e não mudará o seu tempo de internação.

4. Benefícios que poderão ser obtidos - A sua participação neste estudo irá beneficiar as novas técnicas e medicamentos do tratamento do câncer, que diminuem os efeitos colaterais (náuseas, vômitos, mal estar).

5. Procedimentos alternativos que possam ser vantajosos para o indivíduo - Se a senhora não quiser realizar este procedimento antes da cirurgia, poderá fazer a cirurgia normalmente, não alterando o tratamento previamente proposto.

\section{IV - ESCLARECIMENTOS DADOS PELO PESQUISADOR SOBRE GARANTIAS DO SUJEITO DA PESQUISA CONSIGNANDO:}

1. Acesso, a qualquer tempo, às informações sobre procedimentos, riscos e benefícios relacionados à pesquisa, inclusive para dirimir eventuais dúvidas.

2. Liberdade de retirar seu consentimento a qualquer momento e deixar de participar do estudo, sem que isto traga prejuízo à continuidade da assistência médica.

3. Salvaguarda da confidencialidade, sigilo e privacidade.

4. Disponibilidade de assistência no HCFMUSP, por eventuais danos à saúde, decorrentes da pesquisa, estando a disposição o Pronto Socorro de Ginecologia e os pesquisadores, nos telefones 3069-6647 e 3082-7394. 
5. Viabilidade de indenização por eventuais danos à saúde decorrentes da pesquisa.

\section{INFORMAÇÕES DE NOMES, ENDEREÇOS E TELEFONES DOS RESPONSÁVEIS PELO ACOMPANHAMENTO DA PESQUISA, PARA CONTATO EM CASO DE INTERCORRÊNCIAS CLÍNICAS E REAÇÕES ADVERSAS.}

Dra. Maria Luiza Nogueira Dias Genta

T: 3069-6000 ramal 6242

Cel: $9103-8268$

\section{OBSERVAÇÕES COMPLEMENTARES}

\section{VII - CONSENTIMENTO PÓS-ESCLARECIDO}

Declaro que, após convenientemente esclarecido pelo pesquisador e ter entendido o que me foi explicado, consinto em participar do presente Protocolo de Pesquisa.

São Paulo, 30 de novembro de 2004.

Assinatura do sujeito da pesquisa ou responsável legal
Assinatura do pesquisador
(carimbo ou nome Legível) 
7.2 ANEXO B

\begin{tabular}{cccccccc}
\hline Grupo 1 & RG - HC & Idade & $\begin{array}{c}\text { Colesterol } \\
\text { total }\end{array}$ & LDL & HDL & VLDL & Triglicérides \\
\hline AAG & 13486067J & 86 & 214 & 140 & 42 & 32 & 162 \\
\hline GFJS & $5285396 \mathrm{D}$ & 64 & 124 & 63 & 40 & 21 & 104 \\
\hline LAS & $6022514 \mathrm{~B}$ & 46 & 254 & 169 & 54 & 31 & 156 \\
\hline OCA & $13654794 \mathrm{~A}$ & 51 & 198 & 108 & 46 & 44 & 220 \\
\hline $\begin{array}{c}\text { VMDFS } \\
\text { 3368839E }\end{array}$ & 57 & 199 & 139 & 36 & 24 & 120 \\
\hline $\begin{array}{c}\text { Média } \pm \\
\text { d.p. }\end{array}$ & & $60,8 \pm 15,6$ & $198 \pm 47$ & $124 \pm 40$ & $44 \pm 7$ & $30 \pm 9$ & $152 \pm 45$ \\
\hline d.p.- desvio padrão & & & & & & & \\
\hline
\end{tabular}

\begin{tabular}{cccccccc}
\hline Grupo 2 & RG-HC & Idade & $\begin{array}{c}\text { Colesterol } \\
\text { total }\end{array}$ & LDL & HDL & VLDL & Triglicérides \\
\hline RNCDA & $3277456 \mathrm{~B}$ & 28 & 287 & 187 & 51 & 49 & 243 \\
\hline RAR & $2870576 \mathrm{D}$ & 41 & 221 & 128 & 56 & 37 & 185 \\
\hline EBDL & 13667360I & 49 & 209 & 106 & 73 & 30 & 152 \\
\hline $\begin{array}{c}\text { Média } \pm \\
\text { d.p. }\end{array}$ & & $39,3 \pm 10,6$ & $239 \pm 42$ & $140 \pm 42$ & $60 \pm 12$ & $39 \pm 10$ & $193 \pm 46$ \\
\hline
\end{tabular}

d.p.- desvio padrão 
7.3 ANEXO C

PACIENTE AAG

\begin{tabular}{|c|c|c|c|c|}
\hline \multirow{2}{*}{ Tempo } & \multicolumn{4}{|c|}{ Concentração Plasmática } \\
\cline { 2 - 5 } & \multicolumn{2}{|c|}{$\left[{ }^{3} \mathrm{H}\right]$-oleato de paclitaxel } & \multicolumn{2}{|c|}{$\left[{ }^{14} \mathrm{C}\right]$-LDE } \\
\hline & $\mathrm{cpm}$ & $\%$ & $\mathrm{cpm}$ & $\%$ \\
\hline 5 minutos & 137 & 100 & 467 & 100 \\
\hline 1 hora & - & - & 342 & 73 \\
\hline 2 horas & 110 & 80 & 236 & 51 \\
\hline 4 horas & 36 & 26 & 71 & 15 \\
\hline
\end{tabular}


PACIENTE GFJS

\begin{tabular}{|c|c|c|c|c|}
\hline \multirow{2}{*}{ Tempo } & \multicolumn{4}{|c|}{ Concentração Plasmática } \\
\cline { 2 - 5 } & \multicolumn{3}{|c|}{$\left[{ }^{3} \mathrm{H}\right]$-oleato de paclitaxel } & \multicolumn{2}{|c|}{$\left.{ }^{14} \mathrm{C}\right]$-LDE } \\
\cline { 2 - 5 } & $\mathrm{cpm}$ & $\%$ & $\mathrm{cpm}$ & $\%$ \\
\hline 5 minutos & 97,5 & 100 & 97,75 & 100 \\
\hline 15 minutos & 91,53 & 90 & 93,25 & 91 \\
\hline 30 minutos & 86,73 & 86,1 & 90,85 & 91 \\
\hline 1 hora & 81,18 & 84,7 & 85,28 & 90,4 \\
\hline 2 horas & 67,83 & 69,2 & 69,65 & 69,3 \\
\hline 4 horas & 54,35 & 51,8 & 54,28 & 49,6 \\
\hline 6 horas & 48,10 & 48,2 & 47,48 & 48,6 \\
\hline 8 horas & 43,05 & 40,6 & 43,48 & 43,1 \\
\hline 10 horas & 38,25 & 39,2 & 38,23 & 39,1 \\
\hline 12 horas & 29,53 & 34 & 27,33 & 31,6 \\
\hline 24 horas & 16,68 & 10,9 & 13,15 & 7 \\
\hline
\end{tabular}


PACIENTE LAS

\begin{tabular}{|c|c|c|c|c|}
\hline \multirow{3}{*}{ Tempo } & \multicolumn{4}{|c|}{ Concentração Plasmática } \\
\hline & \multicolumn{2}{|c|}{$\left[{ }^{3} \mathrm{H}\right]$-oleato de paclitaxel } & \multicolumn{2}{|c|}{$\left[{ }^{14} \mathrm{C}\right]-\mathrm{LDE}$} \\
\hline & $\mathrm{cpm}$ & $\%$ & cpm & $\%$ \\
\hline 5 minutos & 114 & 100 & 547 & 100 \\
\hline 15 minutos & 110 & 97 & 535 & 98 \\
\hline 30 minutos & 97 & 85 & 509 & 93 \\
\hline 1 hora & 105 & 92 & 499 & 91 \\
\hline 2 horas & 115 & 100 & 403 & 74 \\
\hline 4 horas & 113 & 99 & 343 & 63 \\
\hline 6 horas & 122 & 107 & 307 & 56 \\
\hline 8 horas & 104 & 91 & 286 & 52 \\
\hline 10 horas & 76 & 66 & 297 & 54 \\
\hline 12 horas & 73 & 64 & 252 & 46 \\
\hline 24 horas & 35 & 31 & 108 & 20 \\
\hline
\end{tabular}


PACIENTE VMDFS

\begin{tabular}{|c|c|c|c|c|}
\hline \multirow{2}{*}{ Tempo } & \multicolumn{4}{|c|}{ Concentração Plasmática } \\
\cline { 2 - 5 } & {$\left[{ }^{3} \mathrm{H}\right]-$-oleato de paclitaxel } & \multicolumn{2}{|c|}{$\left[{ }^{14} \mathrm{C}\right]$-LDE } \\
\cline { 2 - 5 } & $\mathrm{cpm}$ & $\%$ & $\mathrm{cpm}$ & $\%$ \\
\hline 5 minutos & 46 & 100 & 203 & 100 \\
\hline 30 minutos & 43 & 93 & 163 & 80 \\
\hline 2 horas & 37 & 80 & 175 & 86 \\
\hline 6 horas & 33 & 72 & 150 & 74 \\
\hline 8 horas & 22 & 48 & 134 & 66 \\
\hline 10 horas & 21 & 46 & 98 & 48 \\
\hline 24 horas & 17 & 37 & 62 & 31 \\
\hline
\end{tabular}


PACIENTE OCA

\begin{tabular}{|c|c|c|c|c|}
\hline \multirow{3}{*}{ Tempo } & \multicolumn{4}{|c|}{ Concentração Plasmática } \\
\hline & \multicolumn{2}{|c|}{$\left[{ }^{3} \mathrm{H}\right]$-oleato de paclitaxel } & \multicolumn{2}{|c|}{$\left[{ }^{14} \mathrm{C}\right]-\mathrm{LDE}$} \\
\hline & $\mathrm{cpm}$ & $\%$ & cpm & $\%$ \\
\hline 5 minutos & 87 & 100 & 479 & 100 \\
\hline 30 minutos & 88 & 100 & 460 & 96 \\
\hline 1 hora & 80 & 92 & 403 & 84 \\
\hline 2 horas & 79 & 91 & 359 & 75 \\
\hline 4 horas & 76 & 87 & 344 & 72 \\
\hline 6 horas & 67 & 77 & 305 & 64 \\
\hline 8 horas & 53 & 61 & 240 & 50 \\
\hline 24 horas & 32 & 37 & 105 & 22 \\
\hline
\end{tabular}


PACIENTE RNCA

\begin{tabular}{|c|c|c|}
\hline \multirow{3}{*}{ Tempo } & \multicolumn{2}{|c|}{ Concentração Plasmática } \\
\hline & \multicolumn{2}{|c|}{$\left[{ }^{3} \mathrm{H}\right]$-paclitaxel } \\
\hline & cpm & $\%$ \\
\hline 5 minutos & 150 & 100 \\
\hline 15 minutos & 139 & 99 \\
\hline 30 minutos & 115 & 77 \\
\hline 1 hora & 118 & 79 \\
\hline 2 horas & 93 & 62 \\
\hline 4 horas & 73 & 49 \\
\hline 6 horas & 70 & 47 \\
\hline 8 horas & 77 & 51 \\
\hline 10 horas & 53 & 35 \\
\hline 24 horas & 18 & 12 \\
\hline
\end{tabular}


PACIENTE RAR

\begin{tabular}{|c|c|c|}
\hline \multirow{2}{*}{ Tempo } & \multicolumn{2}{|c|}{ Concentração Plasmática } \\
\cline { 2 - 3 } & \multicolumn{2}{|c|}{$\left[{ }^{3} \mathrm{H}\right]$-paclitaxel } \\
\cline { 2 - 3 } & $\mathrm{cpm}$ & 100 \\
\hline 3 minutos & 198 & 94 \\
\hline 1 minutos & 187 & 51 \\
\hline 2 horas & 101 & 50 \\
\hline 4 horas & 100 & 29 \\
\hline 6 horas & 58 & 22 \\
\hline 8 horas & 44 & 7 \\
\hline 10 horas & 15 & 6 \\
\hline 24 horas & 14 & 6 \\
\hline
\end{tabular}


PACIENTE EB

\begin{tabular}{|c|c|c|}
\hline \multirow{2}{*}{ Tempo } & \multicolumn{2}{|c|}{ Concentração Plasmática } \\
\cline { 2 - 3 } & \multicolumn{2}{|c|}{$\left[{ }^{3} \mathrm{H}\right]$-paclitaxel } \\
\cline { 2 - 3 } & $\mathrm{cpm}$ & 100 \\
\hline 15 minutos & 492 & 49 \\
\hline 30 minutos & 242 & 41 \\
\hline 1 hora & 200 & 25 \\
\hline 2 horas & 122 & 17 \\
\hline 4 horas & 84 & 15 \\
\hline 6 horas & 75 & 4 \\
\hline 8 horas & 21 & 1 \\
\hline 24 horas & 3 & 2 \\
\hline
\end{tabular}




\section{REFERÊNCIAS}

1 Parkin DM, Bray FI, Devesa SS. Cancer burden in the year 2000. The global picture. Eur J Cancer. 2001; 37(Suppl 8):4-66.

2 Estimativa 2005 - Incidência de Câncer no Brasil [Instituto Nacional do Câncer (INCA), Ministério da Saúde]. Rio de Janeiro; 2004.

3 Inquérito domiciliar sobre comportamentos de risco e morbidade referida de doenças e agravos não transmissíveis [online] [Instituto Nacional de Câncer; Ministério da Saúde]. Rio de Janeiro; 2003. Disponível em: http://www.inca.gov.br/publicacoes/publicacao inquerito22 06.pdf

4 Concurrent chemoradiation for cervical cancer: Clinical announcement [National Cancer Institute (NCl)]. Washington; 1999.

5 Buda A, Fossati R, Colombo N, Fei F, Floriani I, Alletti DG, Katsaros D, Landoni F, Lissoni A, Malzoni C. Randomized trial of neoadjuvante chemotherapy comparing paclitaxel, ifosfamide, and cisplatin with ifosfamide and cisplatin followed by radical surgery in patients with locally advanced squamous cell cervical carcinoma: the SNAP01 (Studio Neo-Adjuvante Portio) Italian Colaborative Study. J Clin Oncol. 2005; 23:4137-45.

6 Jemal A, Tiwari RC, Murray T, Ghafoor A, Samuels A, Ward E, Feuer EJ, Thun MJ. Cancer statistics, 2004. CA Cancer J Clin. 2004; 54:8-29. 
7 Whittemore AS. Characteristics relating to ovarian cancer risk: implications for prevention and detection. Gynecol Oncol. 1994; 55(Suppl 3, Pt 2):15-9.

8 Agarwal R, Kaye SB. Prognostic factors in ovarian cancer: how close are we to a complete picture? Ann Oncol. 2005; 16:4-6.

9 Linasmita V, Pattaraarchachai J, Daengdeelert P. Prognostic factors for survival of epithelial ovarian cancer. Int J Gynaecol Obstet. 2004; 85:66-9.

10 Gruppy AE, Nathan PD, Rustin GJS. Epithelial ovarian cancer: a review of current management. Clin Oncol. (R Coll Radiol) 2005; 17:399-411.

11 Ozols RF, Bundy BN, Greer BE, et al.. Phase III trial of carboplatin and paclitaxel compared with cisplatin and paclitaxel in patients with optimally resected stage III ovarian cancer: a Gynecologic Oncology Group study. J Clin Oncol. 2003; 21:3194-200.

12 Diczfalusy E. Menopause, developing countries and the $21^{\text {st }}$ century. Acta Obstet Gynecol Scand Suppl. 1986; 134:45-57.

13 Souen JS, Carvalho JP, Pinotti JA. Manual de câncer genital feminino. São Paulo: Roca; 2001. p.238-242. 
14 Ball HG, Blessing JA, Lentz SS, Mutch DG. A phase II trial of paclitaxel in patients with advanced or recurrent adenocarcinoma of the endometrium: A Gynecologic Oncology Group study. Gynecol Oncol. 1996; 62:278-81.

15 Lincoln S, Blessing JA, Lee RB, Rocereto TF. Activity of paclitaxel as second-line chemoterapy in endometrial carcinoma: a Gynecologic Oncology Group study. Gynecol Oncol. 2003; 88:277-81.

16 Eriksson M, Berglund L, Rudling M, Henriksson P, Angelin B. Effects of estrogen on low density lipoprotein metabolism in males. Short-term and long-term studies during hormonal treatment of prostatic carcinoma. J Clin Invest. 1989; 84:802-10.

17 Ho YK, Smith RG, Goldstein JL. Low-density lipoprotein (LDL) receptor activity in human acute myelogenous leukemia cells. Blood. 1978; 52:1099114.

18 Maranhão RC, Cesar TB, Pedroso MTB, Hirata $\mathrm{MH}$, Mesquita $\mathrm{CH}$. Metabolic behavior in rats of a nonprotein microemulsion resembling LDL. Lipids. 1993; 28:691-96.

19 Maranhão RC, Garicochea B, Silva EL, Dorlhiac-Llacer P, Pileggi FJC, Chamone, DAF. Increased plasma removal of microemulsions resembling the lipid phase of low-density lipoproteins (LDL) in patients with acute 
myeloid leukemia: a possible new strategy for the treatment of the disease. Brazilian J Med Biol Res. 1992; 25:1003-7.

20 Maranhão RC, Garicochea B, Silva EL, Dorlhiac-Llacer P, Cadena SM, Coelho IJ, Meneghetti JC, Pileggi FJ, Chamone DA. Plasma kinetics and biodistribution of a lipid emulsion resembling low-density lipoprotein in patients with acute leukemia. Cancer Res. 1994; 54:4660-6.

21 Jackson RL, Morrisett JD, Gotto AM Jr. Lipoprotein structure and metabolism. Physiol Rev. 1976; 56:259-316.

22 Calvert GD, Abbey M. Plasma lipoproteins, apolipoproteins, and proteins concerned with lipid metabolism. Adv Clin Chem. 1985; 24:217-98.

23 Dietschy JM, Turley SD, Spady DK. Role of liver in the maintenance of cholesterol and low density lipoprotein homeostasis in different animal species, including humans. J Lipid Res. 1993; 34:1637-59.

24 Goldstein JL, Ho YK, Basu SK, Brown MS. Binding site on macrophages that mediates uptake and degradation of acetylated low density lipoprotein, producing massive cholesterol deposition. Proc Natl Acad Sci USA. 1979; 76:333-7. 
25 Barclay M, Cogin GE, Escher GC, Kaufman RJ, Kidder ED, Petremann ML. Human plasma lipoproteins, I. In normal women and in women with advanced carcinoma of the breast. Cancer. 1955; 8:253-60.

26 Bases RE, Krakoff IH. Studies of serum cholesterol levels in leukemia. J Reticuloendothel Soc. 1965; 85:8-14.

27 Nydegger UE, Butler RE. Serum lipoprotein levels in patients with cancer. Cancer Res. 1972; 32:1756-60.

28 Che HW, Kandutsch AA, Heininger HJ, Meier H. Elevated sterol synthesis in lymphocytic leukemia cells from two imbred straims of mice. Cancer Res. 1973; 33:2774-8.

29 Philippot JR, Cooper AG, Wallach DFH. Regulation of cholesterol synthesis by normal and leukemic (L2C) guinea pig lymphocites. Proc Natl Acad Sci USA. 1977; 74:956-9.

30 Heininger HJ, Chen HW, Applegate OLJr, Schatcter LP, Schatcter BZ, Anderson PN. Elevated synthesis of cholesterol in human leukemic cells. $J$ Mol Med. 1976; 1:109-15.

31 Gal D, Ohashi M, MacDonald PC, Bushsbaum HJ, Simpson ER. Lowdensity lipoprotein as a potential vehicle for chemotherapeutic agents and 
radionucleotides in the management of gynecologic neoplasms. Am J Obstet Gynecol. 1981; 139:877-85.

32 Vitols S, Gahrton G, Öst A, Petreson C. Elevated low density lipoprotein receptor activity in leukemic cells with monocytic differentiation. Blood. 1984; 63:1186-93.

33 Vitols S, Gahrton G, Petreson C, Björkholm, M. Hypocholesterolaemia in malignacy due to elevated low- density-lipoprotein-receptor activity in tumour cells: evidence from studies in patients with leukemia. Lancet. 1985; 2:11504.

34 Budd D, Ginsberg H. Hypocholesterolemia and acute myelogenous leukemia. Association between disease activity and plasma low-density lipoprotein cholesterol concentrations. Cancer. 1986; 58:1361-5.

35 Henriksson, P, Eriksson M, Ericsson S, Rudling M, Stege R, Berglund L, Angelin B. Hypocholesterolaemia and increased elimination of low-density lipoproteins in metastatic cancer of the prostate. Lancet. 1989; 2:1178-80.

36 Rudling MJ, Angelin B, Peterson CO, Collins VP. Low density lipoprotein receptor activity in human intracranial tumors and its relation to the cholesterol requirement. Cancer Res. 1990; 50:483-87. 
37 Vitols S, Peterson C, Larsson O, Holm P, Aberg B. Elevated uptake of low density lipoproteins by human lung cancer tissue in vivo. Cancer Res. 1992; $52: 6244-7$

38 Pekkanen J, Nissineen A, Punscar S, Karvonen MJ. Short- and long-term association of serum cholesterol with mortality. The 25-year follow-up of the Finnish cohorts of the seven countries study. Am J Epidemiol. 1992; 135:1251-8.

39 Iribarren C, Reed DM, Chen R, Yano K, Dwyer JH. Low serum cholesterol and mortality. Which is the cause and which is the effect? Circulation. 1995; 92:2396-403.

40 Niendorf A, Nagele H, Gerding D, Meyer-Pannwitt U, Gebhardt A. Increased LDL receptor mRNA expression in colon cancer is correlated with a rise in plasma cholesterol levels after curative surgery. Int $J$ Cancer. 1995; 61:461-4.

41 Rudling MJ, Collins VP, Peterson CO. Delivery of aclacinomycin A to human glioma cells in vitro by the low-density lipoprotein pathway. Cancer Res. 1983; 43:4600-5. 
42 Lundberg B. Preparation of drug-low density lipoprotein complexes for delivery of antitumoral drugs via the low density lipoprotein pathway. Cancer Res. 1987; 47:4105-08.

43 Samadi-Baboli M, Favre G, Bernadou J, Berg D, Soula G. Comparative study of the incorporation of ellipticine-esters into low density lipoprotein (LDL) and selective cell uptake of drug--LDL complex via the LDL receptor pathway in vitro. Biochem Pharmacol. 1990; 40:203-12.

44 Rensen PC, Schiffelers RM, Versluis AJ, Bijsterbosch MK, Van KuijkMeuwissen ME, Van Berkel TJ. Human recombinant apolipoprotein Eenriched liposomes can mimic low-density lipoproteins as carriers for the site-specific delivery of antitumor agents. Mol Pharmacol. 1997; 52:445-55.

45 Maranhão RC, Roland IA Transfer of phospholipids and cholesterol from triglyceride-rich emulsions to HDL in rats treated with alloxan, propylthiouracil or ethanol. Braz J Med Biol Res. 1993; 26:109-18.

46 Maranhão RC, Roland IA, Tofoletto O, Ramires JA, Gonçalves RP, Mesquita $\mathrm{CH}$, Pileggi F. Plasma kinetic behavior in hyperlipidemic subjects of a lipidic microemulsion that binds to low density lipoprotein receptors. Lipids. $1997 ; 32: 627-33$. 
47 Hirata RD, Hirata $\mathrm{MH}$, Mesquita $\mathrm{CH}$, Cesar TB, Maranhão RC. Effects of apolipoprotein B-100 on the metabolism of a lipid microemulsion model in rats. Biochim Biophys Acta. 1999; 1437:53-62.

48 Ades A, Carvalho JP, Graziani SR, Amancio RF, Souen J S, Pinotti JA, Maranhão RC. Uptake of a cholesterol-rich emulsion by neoplastic ovarian tissues. Gynecol Oncol. 2001; 82:84-7.

49 Graziani SR, Igreja FAF, Hegg R, Meneghetti C, Brandizzi LI, Barboza R, Amâncio RF, Pinotti JA, Maranhão RC. Uptake of a cholesterol-rich emulsion by breast cancer. Gynecol Oncol. 2002; 85:493-97.

50 Maranhão RC, Graziani SR, Yamaguchi N, Melo RF, Latrilha MC, Rodrigues DG, Couto RD, Schreier S, Buzaid AC. Association of carmustine with a lipid emulsion: in vitro, in vivo and preliminary studies in cancer patients. Cancer Chemother Pharmacol. 2002; 49:487-98.

51 Hungria VT, Latrilha MC, Rodrigues DG, Bydlowski SP, Chiattone CS, Maranhão RC. Metabolism of a cholesterol-rich microemulsion (LDE) in patients with multiple myeloma and a preliminary clinical study of LDE as a drug vehicle for the treatment of the disease. Cancer Chemother Pharmacol. $2004 ; 53: 51-60$. 
52 Valduga CJ, Fernandes DC, Lo Prete AC, Azevedo CH, Rodrigues DG, Maranhão RC. Use of a cholesterol-rich microemulsion that binds to lowdensity lipoprotein receptors as vehicle for etoposide. J Pharm Pharmacol. 2003; 55:1615-22.

53 Azevedo $\mathrm{CH}$, Carvalho JP, Valduga CJ, Maranhao RC. Plasma kinetics and uptake by the tumor of a cholesterol-rich microemulsion (LDE) associated to etoposide oleate in patients with ovarian carcinoma. Gynecol Oncol. 2005; 97:178-82.

54 Rowinsky EK, Cazenave LA, Donehover RC. Taxol: a novel investigational antimicrotubule agent. J Natl Cancer Inst. 1990; 82:1247-59.

55 Wani MC, Taylor HL, Wall ME, Coggon P, McPhail AT. Plant antitumor agents. VI. The isolation and structure of taxol, a novel antileukemic and antitumor agent from Taxus brevifolia. J Am Chem Soc. 1971; 93:2325-7.

56 Horwitz SB. Mechanism of action of taxol. Trends Pharmacol Sci. 1992; 13:134-6.

57 Schiff PB, Horwitz SB. Taxol stabilizes microtubules in mouse fibroblast cells. Proc Natl Acad Sci USA. 1980; 77:1561-5. 
58 Rowinsky EK. Update on the antitumor activity of paclitaxel in clinical trials. Ann Pharmacother. 1994; 28:S18-22.

59 Manfredi JJ, Horwitz SB. Taxol: an antimitotic agent with a new mechanism of action. Pharmacol Ther. 1984; 25:83-125.

60 Horwitz SB, Cohen D, Rao S, Ringell, Shen HJ, Yang CP. Taxol: mechanisms of action and resistance. J Natl Cancer Inst Monogr. 1993; $15: 55-61$.

61 Balasubramanian SV, Alderfer JL. Straubinger Solvent and concentrationdependent molecular interactions of taxol (Paclitaxel). J Pharm Sci. 1994; 83:1470-6.

62 Trissel LA. Pharmaceutical properties of paclitaxel and their effects on preparation and administration. Pharmacotherapy. 1997; 17(Suppl 5, Pt 2):133-9.

63 Tarr BD, Sambandan TG, Yalkowsky SH. A new parenteral emulsion for the administration of taxol. Pharm Res. 1987; 4:162-5.

64 Weiss RB, Donehower RC, Wiemik PH, Ohnuma T, Gralla RJ, Trump DL, Baker JRJr, Van Echo DA, Von Hoff DD, Levland-Jones B. Hypersensitivity reactions from taxol. J Clin Oncol. 1990; 8:1263-8. 
65 Rowinsky EK, Burke PJ, Karp JE, Tucker RW, Ettinger DS, Danehower RC. Phase I and pharmacodynamic study of taxol in refractory acute leukemias. Cancer Res. 1989; 49:4640-7.

66 Liebmann J, Cook JA, Mitchell JB. Cremophor EL, solvent for paclitaxel, and toxicity. Lancet. 1993; 342:1428.

67 Sharma US, Balasubramanian SV, Straubinger RM. Pharmaceutical and physical properties of paclitaxel (Taxol) complexes with cyclodextrins. $J$ Pharm Sci. 1995; 84:1223-30.

68 Sharma A, Straubinger RM. Novel taxol formulations: preparation and characterization of taxol-containing liposomes. Pharm Res. 1994; 11:889-96.

69 Sharma A, Chelvi TP, Kaur J, Ralhan R. Thermosensitive liposomal taxol formulation: heat-mediated targeted drug delivery in murine melanoma. Melanoma Res. 1998; 8:240-4.

70 Lundberg BB. Ether lipids enhance the cytotoxic effect of teniposide and paclitaxel in liposomes against leukaemic cells in culture. Anticancer Drug Des. $1997 ; 12: 503-13$. 
71 Kan P, Chen ZB, Lee CJ, Chu IM. Development of nonionic surfactant/phospholipid o/w emulsion as a paclitaxel delivery system. $J$ Control Release. 1999; 58:271-8.

72 Zhang X, Burt HM, Mangold G, Dexter D, Von Hoff D, Mayer L, Hunter WL. Anti-tumor efficacy and biodistribution of intravenous polymeric micellar paclitaxel. Anticancer Drugs. 1997; 8:696-701.

73 Cavalli R, CaputoO, GascoMR. Preparation and characterization of solid lipid nanospheres containing paclitaxel. Eur J Pharm Sci. 2000; 10:305-9.

74 Fonseca C, Simões S, Gaspar R. Paclitaxel-loaded PLGA nanoparticles: preparation, physicochemical characterization and in vitro anti-tumoral activity. J Control Release. 2002; 83:273-286.

$75 \mathrm{Mu} \mathrm{L}$, Feng SS. A novel controlled release formulation for the anticancer drug paclitaxel (Taxol): PLGA nanoparticles containing vitamin E TPGS. J Control Release. 2003; 86:33-48.

76 Li C, Yu DF, Newman RA, Cabral F, Stephens LC, Hunter N, Milas L, Wallace S. Complete regression of well-established tumors using a novel water-soluble poly(L-glutamic acid)-paclitaxel conjugate. Cancer Res. 1998; 58:2404-9. 
77 Masquelier M, Vitols S, Palsson M, Mars U, Larsson BS, Peterson CO. Low density lipoprotein as a carrier of cytostatics in cancer chemotherapy: study of stability of drug-carrier complexes in blood. J Drug Target. 2000; 8:155-64.

78 Deutsch HM, Glinski JA, Hernandez M, Haugwitz RD, Narayanan VL, Suffness M, Zalkow LH. Synthesis of congeners and prodrugs. 3. Watersoluble prodrugs of taxol with potent antitumor activity. J Med Chem. 1989; 32:788-92.

79 Mathew AE, Mejillano MR, Nath JP, Himes RH, Stella VJ. Synthesis and evaluation of some water-soluble prodrugs and derivatives of taxol with antitumor activity. J Med Chem. 1992; 35:145-51.

80 Jayasinghe LR, Datta A, Ali SM, Zygmunt J, Vander Velde DG, Georg GI. Structure-activity studies of antitumor taxanes: synthesis of novel C-13 side chain homologated taxol and taxotere analogs. J Med Chem. 1994; 37:29814.

81 Bradley MO, Swindell CS, Anthony FH, Witman PA, Devanesan P, Webb NL, Baker SD, Wolff AC, Donehower RC. Tumor targeting by conjugation of DHA to paclitaxel. J Control Release. 2001; 74:233-6. 
82 Harries M, O’Donnell A, Scurr M, Reade S, Cole C, Judson I, Greystoke A, Twelves C, Kaye S. Phase I/II study of DHA-paclitaxel in combination with carboplatin in patients with advanced malignant solid tumours. $\mathrm{Br} J$ Cancer. $2004 ; 91: 1651-5$

83 Feng X, Yuan YJ, Wu JC. Synthesis and evaluation of water-soluble paclitaxel prodrugs. Bioorg Med Chem Lett. 2002; 12:3301-3.

84 Lundberg BB, Risovic V, Ramaswamy M, Wasan KM. A lipophilic paclitaxel derivative incorporated in a lipid emulsion for parenteral administration. J Control Release. 2003; 86:93-100.

85 Rodrigues DG, Maria DA, Fernandes DC, Valduga CJ, Couto RD, Ibanez OC, Maranhão RC. Improvement of paclitaxel therapeutic index by derivatization and association to a cholesterol-rich microemulsion: in vitro and in vivo studies. Cancer Chemother Pharmacol. 2005; 55:565-76.

86 Lundberg B. Preparation of drug-low density lipoprotein complexes for delivery of antitumoral drugs via the low density lipoprotein pathway. Cancer Res. 1987; 47:4105-08.

87 Siedel J, Hagele EO, Ziegenhorn J, Wahlefeld AW. Reagent for the enzymatic determination of serum total cholesterol with improved lipolytic efficiency. Clin Chem. 1983; 29:1075-80. 
88 III Diretrizes Brasileiras sobre Dislipidemias da Sociedade Brasileira de Cardiologia, 2001

89 Friedewald WT, Levy RI, Fredricson DS. Estimation of the concentration of low density lipoprotein cholesterol in plasma, without use of the preparative ultra centrifuge. Clin Chem. 1972; 18:499-502.

90 Mesquita C.H. Análise compartimental auxiliar. São Paulo: Institutos de Pesquisa Energéticas e Nucleares (IPEN), [Publicações IPEN]; 1994.

91 Folch J, Lees M, Stanley HS. A simple method for the isolation and purification of total lipids from animal tissues. J Biol Chem. 1957; 226:497509.

92 Goble S, Bear HD. Emerging role of taxanes in adjuvant and neoadjuvant therapy for breast cancer: the potential and the questions. Surg Clin North Am. 2003; 83:943-71.

93 Seidman AD, Hochhauser D, Gollub M, Edelman B, Yao TJ, Hudis CA, Francis P, Fennelly D, Gilewski T A, Moynahan ME, Currie V, Baselga J, Tong W, O’Donaghue M, Salvaggio R, Auguste L, Spriggs D, Norton L. Ninety-six-hour paclitaxel infusion after progression during short taxane 
exposure: a Phase II pharmacokinetic and pharmacodynamic study in metastatic breast cancer. J Clin Oncol. 1996; 6:1877-84.

94 Rao GG, Rogers P, Drake RD, Nguyen P, Coleman RL. Phase I clinical trial of weekly paclitaxel, weekly carboplatin, and concurrent radiotherapy for primary cervical cancer. Gynecol Oncol. 2005; 96:168-72.

95 Woo HL, Swenerton KD, Hoskins PJ. Taxol is active in platinum-resistant endometrial adenocarcinoma. Am J Clin Oncol. 1996; 19:290-1. 